EMPIRICAL PROPERTIES OF DIVERSION RATIOS

Christopher T. Conlon

Julie Holland Mortimer

WORKING PAPER 24816 
NBER WORKING PAPER SERIES

\title{
EMPIRICAL PROPERTIES OF DIVERSION RATIOS
}

\author{
Christopher T. Conlon \\ Julie Holland Mortimer \\ Working Paper 24816 \\ http://www.nber.org/papers/w24816 \\ NATIONAL BUREAU OF ECONOMIC RESEARCH \\ 1050 Massachusetts Avenue \\ Cambridge, MA 02138 \\ July 2018, Revised September 2020
}

A pre-cursor to this paper was circulated under the title "An Experimental Approach to Merger Analysis." We thank Joe Farrell, Phil Haile, Dennis Carlton, Ken Hendricks, Fiona Scott Morton, Aviv Nevo, Bill Rogerson, Ralph Winter, Dan O'Brien, and seminar participants at: Charles River Associates, Columbia University, the Department of Justice, NYU Stern, the University of Western Ontario, the University of Mannheim, the Bates White Antitrust Conference, the Behavioral Game Theory Workshop, the FTC Microeconomics Conference, 'I.O. Fest' at UC Berkeley, the Dartmouth Winter IO Conference, the NBER Summer Institute, the Penn State Cornell Econometrics and IO Conference, and the antitrust conference at the University of British Columbia, for comments. Chitra Marti provided exceptional research assistance. Special thanks to Jeff Gortmaker for custom updates to PyBLP. Any remaining errors are our own. Financial support for this research was generously provided through NSF grant SES-0617896. The views expressed herein are those of the authors and do not necessarily reflect the views of the National Bureau of Economic Research.

NBER working papers are circulated for discussion and comment purposes. They have not been peer-reviewed or been subject to the review by the NBER Board of Directors that accompanies official NBER publications.

(C) 2018 by Christopher T. Conlon and Julie Holland Mortimer. All rights reserved. Short sections of text, not to exceed two paragraphs, may be quoted without explicit permission provided that full credit, including $(\odot$ notice, is given to the source. 
Empirical Properties of Diversion Ratios

Christopher T. Conlon and Julie Holland Mortimer

NBER Working Paper No. 24816

July 2018, Revised September 2020

JEL No. L0,L1,L4

\begin{abstract}
$\underline{\text { ABSTRACT }}$
The diversion ratio for products $\mathrm{j}$ and $\mathrm{k}$ can be interpreted as the result of an experiment: increase the price of product $j$, measure the number of consumers who leave product $j$, and then measure the fraction of leavers who switch to a substitute product $\mathrm{k}$. In theory, this is expressed as the ratio of demand derivatives that enter the multi-product Bertrand-Nash first-order condition for a firm. In practice, diversion ratios are also measured from second-choice data or customer switching surveys. We establish a LATE interpretation of diversion ratios, and show how diversion ratios can be obtained from different interventions (price changes, quality changes, assortment changes) and how those different measures relate to one another and to the underlying properties of demand.
\end{abstract}

Christopher T. Conlon

Department of Economics

New York University

Stern School of Business

Henry Kaufman Management Center

$44 \mathrm{~W}$. Fourth St

New York, NY 10012

cconlon@stern.nyu.edu

Julie Holland Mortimer

Department of Economics

Boston College

140 Commonwealth Avenue

Chestnut Hill, MA 02467

and NBER

julie.mortimer.2@bc.edu 


\section{Introduction}

The diversion ratio is one of the best ways economists have for understanding the nature of competition between sellers. As the price of $j$ increases, some consumers reduce purchases

of $j: \frac{\partial q_{j}}{\partial p_{j}}$, and a subset switch to a substitute product $k: \frac{\partial q_{k}}{\partial p_{j}}$. The diversion ratio is defined as the ratio of these two demand derivatives $D_{j k}=\frac{\partial q_{k}}{\partial p_{j}} /\left|\frac{\partial q_{j}}{\partial p_{j}}\right|$. Diversion ratios are useful because they arise in the first-order conditions for Nash-in-prices games when sellers offer differentiated products. Two products with a high degree of differentiation face lower diversion and softer price competition, whereas two products with a high degree of similarity to competing goods face higher diversion and potentially tougher price competition.

Not surprisingly, diversion ratios are a central calculation of interest to antitrust authorities for analyzing horizontal mergers. The current U.S. merger guidelines, released in 2010, place greater weight on diversion ratios relative to concentration measures more commonly used to understand competition in settings with homogeneous goods (e.g., the HerfindahlHirschman Index (HHI)). ${ }^{1}$ In the context of merger reviews, antitrust authorities identify the concept of 'unilateral effects' as being important for understanding the impact of a proposed merger. Unilateral effects of a merger arise when competition between the products of the merged firm is reduced because the merged firm internalizes substitution between its jointly-owned products. ${ }^{2}$ This can lead to an increase in the price of the products of the merged firm, potentially harming consumers. Diversion ratios are the key statistic of interest for measuring unilateral effects. The current U.S. merger guidelines, released in 2010, note:

Diversion ratios between products sold by one merging firm and products sold by the other merging firm can be very informative for assessing unilateral price effects, with higher diversion ratios indicating a greater likelihood of such effects.

Thus, holding competitive responses (and price-cost margins) fixed, antitrust agencies will be more concerned about mergers that involve products with higher diversion ratios, because the scope for price increases due to unilateral effects is thought to be greater.

Although the use of diversion ratios in antitrust policy is well understood theoretically, in practice, one needs to estimate diversion ratios. The U.S. merger guidelines discuss diversion

\footnotetext{
${ }^{1}$ Researchers have pointed out a number of concerns with using concentration measures or other functions of market share to capture the strength of competition. One concern is that such measures require one to define a market; another is that they do not capture the closeness of competition when products are differentiated, as most products are thought to be.

${ }^{2}$ In contrast, the concept of harm via 'coordinated effects' arises if a proposed merger increases the probability that firms in the industry will be able to successfully coordinate their behavior in an anticompetitive way.
} 
ratios as being calculated from an estimated demand system, or observed from consumer survey data or in a firm's course of business. We demonstrate that there is no single measure of diversion, just as there is no single measure of elasticity. Estimates of both diversion and elasticity depend on where one evaluates the demand curve. We provide a treatment effects framework for interpreting different estimates of diversion. For a broad class of discrete choice models (including both random and deterministic utility), an individual is considered "treated" if they choose not to purchase a particular product $j$, and the outcome of interest is whether they choose to purchase the substitute product $k$. This lets us construct an alternate definition of diversion ratios as the fraction of treated individuals who choose the substitute.

We then show how a wide variety of results from the treatment effects literature can be applied to interpret diversion ratios. Our main theoretical result derives the so-called LATE Theorem of Imbens and Angrist (1994) in our discrete-choice diversion ratio setting. We show that a ceteris paribus change in the price of good $j$ identifies a local average of diversion ratios among a group of "compliers" or individuals who used to purchase good $j$ at the original price but no longer do so at the higher price. We then apply several related results from the LATE toolkit. First, we show that while diversion ratios are defined in terms of small price price changes, any product characteristic satisfying a monotonicity requirement can be used to construct an estimate of a diversion ratio. This makes it possible to identify and estimate diversion ratios in environments where quality (or distance from the consumer, etc.) varies but prices do not. Second, we show that second-choice data pertains to a different treatment effect parameter where all individuals who were previously untreated receive treatment (not purchasing $j$ ). This is particularly relevant because it shows how diversion ratios are related to out of stock events (Conlon and Mortimer, 2013) and the second-choice survey data already being used by antitrust authorities. A 2017 commentary on retail mergers released by the UK Competition and Markets Authority (CMA) describes their use of diversion ratios for screening and analyzing mergers, saying:

Diversion ratios can be calculated in a number of different ways, depending on the information available in a particular case. In retail mergers, the CMA has most often used the results of consumer surveys to calculate diversion ratios. The diversion ratio attempts to capture what customers would do in response to an increase in prices. However, it can be difficult to survey a sufficiently large number of customers who would switch in response to a price rise to estimate a robust diversion ratio. Therefore, the CMA asks customers what they would do 
in response to the closure of a store (or stores). ${ }^{3}$

We further analyze diversion ratios using the marginal treatment effects (MTE) framework of Heckman and Vytlacil (2005). We are able to decompose average diversion ratios into individual diversion ratios, which we show are policy invariant structural parameters, and weights on individuals (which are independent of the substitute product $k$ ). We show that the former no longer depend on whether prices, quality, or availability is modified, while the latter do.

This decomposition has several useful applications. One (obvious) implication is that average diversion ratios are bounded by the range of underlying individual diversion ratios. A second implication is that assuming constant diversion ratios imposes strong parametric restrictions on the nature of demand and utility. Only two models exhibit constant diversion: linear demand, and the plain IIA logit model. Thus treating diversion ratios as constant is akin to assuming that demand is well described by these models. The third implication is that we can derive explicit formulas for these weights under the workhorse random coefficients logit model. This allows us to to show precisely how second choice data, small price changes, and changes in other product characteristics trace out different subpopulations, and how the average diversion ratios measured with these interventions relate to one another. This allows us in principle to answer questions like: "If I am interested in the diversion ratio from a small price change, how similar would second choice survey data be?" or "If I only have diversion ratios measured from short run variation in quality? how might this be informative about what would happen if a product were removed from the market entirely?".

We also show how diversion to the outside good $D_{j 0}$ is closely related to our notion of consumer welfare in random coefficients logit type models. We provide novel results linking willingness-to-pay calculations that are commonplace in models of Nash-in-Nash bargaining (and hospital mergers in particular) to the question: "how many consumers would switch to the outside option if product $j$ were no longer available?". We show that for the logit class of models these WTP calculations can be simplified even further as a function of individual own-share $s_{i j}$, and a set of Pareto weights. This is what enables welfare analysis using WTP calculations, even in settings lacking an outside option (as is common in hospital demand).

We highlight the properties laid out above using the well-known examples of the Berry et al. (1999) automobile data and the Nevo (2000b) (fake) cereal data. Our empirical examples examine the role of diversion to best substitutes and to the outside good. We show that capturing both kinds of diversion ratios is important, and can at times be tricky. We

\footnotetext{
${ }^{3}$ See Competition and Markets Authority (2017).
} 
also illustrate that different interventions (price changes, quality changes, product removals) produce different weighting schemes over individual diversion ratios that can at times be quite different. For example, in the BLP automobile data, second choice diversion understates substitution to the outside good when compared to small price changes by around $30 \%$. Moreover, small changes in parametric specifications can lead to large changes in outside good diversion (as well as markups and welfare) even when own-price elasticities appear stable. Other commonly employed shortcuts such as estimating a nested logit with all products in a single nest do a good job recovering the outside good diversion but predictably understate substitution to the closest substitutes.

Taken in total, we recommend that both academic researchers and antitrust practitioners pay careful attention to diversion to the outside good and to close substitutes, even when estimating parametric models of demand. Furthermore, we urge researchers to be aware that the diversion parameter of interest need not coincide with the parameter that is easily estimated from readily available data (such as consumer switching surveys, etc.) though these extra data sources when carefully incorporated may substantially improve parametric demand models.

\subsection{Related Literature}

A second goal of the paper is to bring together two literatures - the applied theoretical literature that motivates the use of diversion for understanding merger impacts, and an applied econometric literature that articulates estimation challenges in settings for which the treatment effect of a policy can vary across individuals and may be measured with error.

By exploring the assumptions required for a credible (quasi)-experimental method of measuring diversion, we connect directly to the theoretical literature discussing the use and measurement of the diversion ratio. ${ }^{4}$ Farrell and Shapiro (2010) suggest that firms themselves may track diversion in their 'normal course of business,' or that diversion ratios may be uncovered in Hart-Scott-Rodino filings. Hausman (2010) argues that the only acceptable way to measure a diversion ratio is as the output from a structural demand system. Reynolds and Walters (2008) examine the use of stated-preference consumer surveys in the UK for measuring diversion.

In spirit, our approach is similar to Angrist et al. (2000), which shows how a cost shock can identify a particular local average treatment effect (LATE) for the price elasticity in a single

\footnotetext{
${ }^{4}$ The focus on measuring substitution away from product $j$ (using second-choice data or stock-outs), rather than on the direct effect of a proposed merger, is more in line with the public finance literature on sufficient statistics Chetty (2009).
} 
product setting. That approach does not extend to a differentiated products setting because the requisite monotonicity condition may no longer be satisfied. Our results demonstrate how a ceteris paribus price change can identify substitution patterns in a multi-product setting. We also highlight the economic content of (even partial) second-choice data, which have been found to be valuable in the literature on structural demand estimation (e.g., Berry et al. (2004)).

The paper proceeds as follows. Section 2 introduces the diversion ratio as an economic object and compares its better known cousin the cross-price elasticity. We establish our theoretical results linking diversion ratios to treatment effects in Section 3. We highlight the theoretical properties of diversion ratios with empirical examples using the BLP auto data and the Nevo (fake) cereal data in Section 4. Section 5 concludes.

\section{What is a diversion ratio?}

We begin by considering a Bertrand-Nash game where firm $f$ sets the prices of products $j \in \mathcal{J}_{f}$ in order to maximize profits. The firm faces marginal costs $c_{j}$ and demand curve $q_{j}(\mathbf{p})$ (where $\mathbf{p}$ is the vector of prices for all goods) and chooses price $p_{j}$ to solve: $\arg \max _{\mathbf{p}_{\mathbf{f}} \in \mathcal{J}_{f}} \pi_{f}(\mathbf{p})=\sum_{j \in \mathcal{J}_{f}}\left(p_{j}-c_{j}\right) \cdot q_{j}(\mathbf{p})$. The best responses for each product $j$ are given by: ${ }^{5}$

$$
\begin{aligned}
\rightarrow p_{j} & =q_{j}(\mathbf{p})\left[-\frac{\partial q_{j}}{\partial P_{j}}(\mathbf{p})\right]^{-1}+c_{j}+\sum_{k \in \mathcal{J}_{f} \backslash j}\left(p_{k}-c_{k}\right) \underbrace{\frac{\partial q_{k}}{\partial P_{j}}(\mathbf{p})\left[-\frac{\partial q_{j}}{\partial P_{j}}(\mathbf{p})\right]^{-1}}_{D_{j k}(\mathbf{p})} \\
p_{j}\left(p_{-j}\right) & =\underbrace{\frac{1}{1+1 / \epsilon_{j j}(\mathbf{p})}}_{\text {Markup }}\left[c_{j}+\sum_{k \in \mathcal{J}_{f} \backslash j}\left(p_{k}-c_{k}\right) \cdot D_{j k}(\mathbf{p})\right] .
\end{aligned}
$$

The best-response function in (1), shows the usual inverse elasticity $\epsilon_{j j}$ (Lerner) markup applied to the marginal cost of $j$. In multi-product pricing problems this term is augmented by the opportunity cost of selling other products $\sum_{k \in \mathcal{J}_{f} \backslash j}\left(p_{k}-c_{k}\right) \cdot D_{j k}(\mathbf{p})$ where the opportunity cost depends on the fraction of consumers who leave $j$ for the substitute $k$ (diversion ratio) and the price cost margins for $k$. One way to think about what a merger does is that it raises the opportunity cost of selling $j$, by incorporating diversion (and price-cost margins)

\footnotetext{
${ }^{5}$ It is common to write the denominator as the absolute value $\left|\frac{\partial q_{j}}{\partial P_{j}}\right|=-\frac{\partial q_{j}}{\partial P_{j}}$ these are equal so long as demand slopes down $\frac{\partial q_{j}}{\partial P_{j}}<0$.
} 
to additional products. This is the central idea in Farrell and Shapiro (2010), and is the reason that diversion features so heavily in the 2010 Horizontal Merger Guidelines.

There is some controversy about whether one should evaluate a merger by solving the system of best responses defined by (1), as in Nevo (2000a), or by measuring how the merger shifts the best-response for each product $j$ in isolation. ${ }^{6}$ A common metric in the latter case is Upward Pricing Pressure (UPP). This measures how the term in brackets from (1) changes when $f$ and $g$ merge:

$$
U P P_{j}=\underbrace{\Delta c_{j}}_{\text {efficiency }}+\sum_{k \in \mathcal{J}_{g}} \underbrace{\left(p_{k}-c_{k}\right) \cdot D_{j k}\left(p_{j}, p_{-j}\right)}_{\Delta \text { opp cost }}
$$

UPP trades off potential marginal cost reductions (efficiency gains) against the increased opportunity cost that arises from diversion to additional products owned by firm $g$ and their respective price-cost margins. Only the sign of $U P P$ is directly interpretable, as it measures the effective change in marginal cost but not price. ${ }^{7}$ It is common in merger analysis to compute the "compensating marginal cost reduction" or the value of $\Delta c_{j}$ which sets $U P P_{j}=0$ for each product $j$.

Whether one does full-merger simulation like Nevo (2000a) or simply looks at the UPP, Diversion ratios are a key feature in the first-order conditions of multi-product firms. In fact, for any study of multi-product firm behavior, the diversion ratio is one of the most important deliverables of any demand system. Later, in Section 3.8, we show how the the willingnessto-pay (WTP) measure of Town and Vistnes (2001); Capps et al. (2003), commonly used in evaluating hospital mergers, and an input into Nash-in-Nash bargaining models (Crawford and Yurukoglu, 2012) is related to diversion to the outside good. In related work, Katz and Shapiro (2003) show that the "aggregate diversion ratio" or total diversion to all products except the outside option is related to the SSNIP and hypothetical monopolist tests that antitrust authorities use to define relevant markets.

The remainder of the paper focuses on two key aspects of diversion ratios: (1) what a ceteris paribus change in price or availability can tell us about diversion ratios; (2) what restrictions are imposed on diversion ratios by parametric models of demand commonly used

\footnotetext{
${ }^{6}$ See, for example, Hausman (2010), Carlton (2010), Schmalensee (2009), Willig (2011), Carlton and Israel (2010), Gotts (2010), and Farrell and Shapiro (2010).

${ }^{7}$ See, for example, Jaffe and Weyl (2013), which incorporates an estimated pass-through rate to map anticipated opportunity cost effects of a merger into price effects. In related work, Miller et al. (2016) and Cheung (2011) find that the price effects of a merger, and errors in predicting these effects, depend on the nature of competition among non-merging firms, and whether prices are strategic substitutes or strategic complements.
} 
by researchers and practitioners.

\subsection{How is diversion different from cross-price elasticity?}

An important question is whether the diversion ratio actually contains different information when compared to the more common measure of substitution, the cross-price elasticity. Recall that the cross price elasticity is defined as: $\epsilon_{j k}=\frac{\partial q_{k}}{\partial P_{j}} \frac{p_{j}}{q_{k}}$ and that the ratio of cross and own price elasticities yields: $\frac{\epsilon_{j k}}{\epsilon_{j j}}=\frac{\frac{\partial q_{k}}{\partial P_{j}}}{\frac{\partial q_{j}}{\partial P_{j}}} \frac{q_{j}}{q_{k}}=-D_{j k} \frac{s_{j}}{s_{k}}$. That is, the diversion ratio can simply be written as the ratio of cross and own price elasticities multiplied by the respective ratio in market shares.

Unlike own-price elasticities where there is a natural relationship between the value of the elasticity and the market power of the firm (Lerner Markup), there is no such relationship for cross-price elasticities. That is, the cross-price elasticity alone is insufficient to calculate a compensating marginal cost reduction. Moreover, larger cross-price elasticities may not even signify closer substitutes. Consider two substitutes: the first has a cross elasticity with $j$ of $\epsilon_{j k}=0.03$ and $s_{k}=0.1$ while the second has a cross-price elasticity of $\epsilon_{j k^{\prime}}=0.01$ and $s_{j}=0.35$. More consumers switch to $k^{\prime}$ than to $k$, even though $k$ has a larger cross-price elasticity. In order to adjust this calculation, one must incorporate the shares (and implicitly calculate the diversion ratio).

Perhaps the most important difference is that there may be cases where the diversion ratio is identified, but the constituent parts $\frac{\partial q_{k}}{\partial P_{j}}, \frac{\partial q_{j}}{\partial P_{j}}$ or $\epsilon_{j k}, \epsilon_{j j}$ are not separately identified. Indeed, we highlight several hypothetical experiments where the diversion ratio (or some average of diversion ratios) can be recovered even when the underlying demands or consumer utilities cannot be. ${ }^{8}$

\section{A Treatment Effects Interpretation of Diversion Ratios}

\subsection{The Wald (1940) Estimator}

Diversion ratios provide a way to answer the question: "What can a price change tell us about substitution patterns?" We begin by considering a ceteris paribus increase in price of good $j$ from $p_{j} \rightarrow p_{j}^{\prime}$ and define the corresponding Wald esimator which compares the ratio

\footnotetext{
${ }^{8}$ The UK CMA survey asking shoppers: "If this store were closed where would you shop?" is a prime example. We could estimate a particular average diversion ratio, but would have no ability to estimate ownor cross-price elasticities.
} 
of the change in sales of $k$ to that of $j .{ }^{9}$ The Wald estimator has the advantage that it is often readily observed from the data for a particular price change:

$$
\operatorname{Wald}\left(p_{j}, p_{j}^{\prime}, x\right)=\frac{q_{k}\left(p_{j}^{\prime}, x\right)-q_{k}\left(p_{j}, x\right)}{-\left(q_{j}\left(p_{j}^{\prime}, x\right)-q_{j}\left(p_{j}, x\right)\right)}
$$

The diversion ratio $D_{j k}\left(p_{j}, x\right) \equiv \frac{\partial q_{k}}{\partial P_{j}}\left(p_{j}, x\right) /-\frac{\partial q_{j}}{\partial P_{j}}\left(p_{j}, x\right)$ can be obtained as the limit of the Wald estimator in (3) where the price increase (or decrease) becomes small, so long as demand slopes strictly downwards $\frac{\partial q_{j}}{\partial P_{j}}<0:{ }^{10}$

$$
\lim _{p_{j}^{\prime} \rightarrow p_{j}} \frac{q_{k}\left(p_{j}^{\prime}, x\right)-q_{k}\left(p_{j}, x\right)}{-\left(q_{j}\left(p_{j}^{\prime}, x\right)-q_{j}\left(p_{j}, x\right)\right)} \rightarrow \frac{\frac{\partial q_{k}}{\partial P_{j}}\left(p_{j}, x\right)}{-\frac{\partial q_{j}}{\partial P_{j}}\left(p_{j}, x\right)} \equiv D_{j k}\left(p_{j}, x\right)
$$

A large literature establishes the connection between Wald estimators like (3) and local average treatment effects (LATE). ${ }^{11}$

\subsection{Discrete Choice and a LATE Theorem}

An easy way to see the connection between the Wald estimator and local average treatment effects is to assume that the demands in (4) are derived from a discrete-choice model of demand, where consumer $i$ has unit demand and faces prices $\left(p_{j}, p_{-j}\right)$. Consumer $i$ selects product $j$ from set $\mathcal{J}$ (which includes an outside or no-purchase option) in order to maximize utility. Define $d_{i j}$ as an indicator for choosing product $j:^{12}$

$$
d_{i j}\left(p_{j}, x\right)= \begin{cases}1 & u_{i j}\left(p_{j}, x\right)>u_{i j^{\prime}}\left(p_{j}, x\right) \text { for all } j^{\prime} \in \mathcal{J} \text { and } j^{\prime} \neq j \\ 0 & \text { o.w. }\end{cases}
$$

\footnotetext{
${ }^{9}$ Implicitly, $x$ contains all other relevant characteristics including: prices of other goods $p_{-j}$, product quality and assortment, etc.. That $p_{j}^{\prime}$ represents a price increase is arbitrary. We could simply exchange $\left(p_{j}, p_{j}^{\prime}\right)$ and consider a price decrease.

${ }^{10}$ This is an application of L'Hôpital's Rule and also requires that $q_{k}$ is differentiable (locally) about $\left(p_{j}, x\right)$. We use $P_{j}$ to denote the argument and $\left(p_{j}, p_{j}^{\prime}\right)$ to denote specific values.

${ }^{11}$ The typical Wald estimator with a binary instrument is $\frac{E\left[Y_{i} \mid Z_{i}=1\right]-E\left[Y_{i} \mid Z_{i}=0\right]}{E\left[T_{i} \mid Z_{i}=1\right]-E\left[T_{i} \mid Z_{i}=0\right]}$. Much of the literature on LATE also establishes the equivalent between the Wald estimator and the linear IV estimator: $y_{i}=$ $\alpha+\beta T_{i}+u_{i}$ with $E\left[u_{i} \mid Z_{i}\right]=0$. We are not interested in that connection in this paper.

${ }^{12}$ This setup includes most RUM's including logit and logit variants. It also encompasses a broad class of both random and deterministic choice models, including a variety of behavioral models where consumers make "mistakes" or fail to consider all available products. Behavioral models fit into the same framework so long as we measure only diversion and not consumer welfare.
} 
In the discrete choice setting, we can derive an equivalent to the LATE theorem of Imbens and Angrist (1994). Our main theoretical result shows that under some relatively weak discrete choice assumptions, a price change can be used to identify the average diversion ratio among a particular set of consumers (compliers).

Proposition 1 (Analogue to LATE Theorem (Imbens and Angrist, 1994)).

Under the following conditions:

(a) Mutually Exclusive and Exhaustive Discrete Choice: $d_{i j} \in\{0,1\}$ and $\sum_{j \in \mathcal{J}} d_{i j}=1$.

(b) Exclusion: $u_{i k}\left(p_{j}, x\right)=u_{i k}\left(p_{j}^{\prime}, x\right)$ for all $k \neq j$ and any $\left(p_{j}, p_{j}^{\prime}\right)$;

(c) Monotonicity: $u_{i j}\left(p_{j}^{\prime}, x\right) \leq u_{i j}\left(p_{j}, x\right)$ for all $i$ and any $\left(p_{j}^{\prime}>p_{j}\right)$; and

(d) Existence of a first-stage: $\operatorname{Pr}\left(d_{i j}\left(p_{j}, x\right)=0\right) \neq \operatorname{Pr}\left(d_{i j}\left(p_{j}^{\prime}, x\right)=0\right)$ for $\left(p_{j}^{\prime}>p_{j}\right)$;

(e) Random Assignment: $\left(u_{i j}\left(P_{j}, x\right), u_{i k}\left(P_{j}, x\right)\right) \perp P_{j}$.

then the Wald estimator from (3):

$$
\frac{q_{k}\left(p_{j}^{\prime}, x\right)-q_{k}\left(p_{j}, x\right)}{-\left(q_{j}\left(p_{j}^{\prime}, x\right)-q_{j}\left(p_{j}, x\right)\right)}=E\left[D_{j k, i}(x) \mid d_{i j}\left(p_{j}, x\right)>d_{i j}\left(p_{j}^{\prime}, x\right)\right]
$$

(Proof in Appendix A.1)

\begin{tabular}{lcc}
\hline Compliance Type & $\left(d_{i j}\left(p_{j}\right), d_{i j}\left(p_{j}^{\prime}\right)\right)$ & Description \\
\hline Always Takers & $(0,0)$ & Don't buy $j$ at either price. \\
Never Takers & $(1,1)$ & Buy $j$ at either price \\
Compliers & $(1,0)$ & Only buy $j$ at lower price $p_{j}<p_{j}^{\prime}$ \\
Defiers & $(0,1)$ & Only buy $j$ at higher price $p_{j}^{\prime}>p_{j}$ \\
\hline Treatment Effects Parameter & Abbreviation & Expression \\
\hline Average Treatment Effect & ATE & $E\left[D_{j k, i}(x)\right]$ \\
Average Treatment on the Treated & ATT & $E\left[D_{j k, i}(x) \mid d_{i j}=0\right]$ \\
Average Treatment on the Untreated & ATUT & $E\left[D_{j k, i}(x) \mid d_{i j}=1\right]$ \\
Local Average Treatment Effect & LATE & $E\left[D_{j k, i}(x) \mid d_{i j}\left(z_{j}\right)=1, d_{i j}\left(z_{j}^{\prime}\right)=0\right]$ \\
\hline
\end{tabular}

Table 1: Description of Compliance Types and Treatment Effects Parameters

In words, the proposition says that the Wald estimator identifies the average diversion ratio among "compliers," those individuals who would buy $j$ at $p_{j}$ but no longer buy $j$ at $p_{j}^{\prime}$ (holding all else $x$ fixed). In other words, the treatment is defined as "not buying $j$ " and define the compliance types in Table 1 . To solidify the connection with the quasiexperimental LATE framework, recognize that our hypothetical price change experiment can be interpreted using the following definitions:

Outcome $Y_{i} \in\{0,1\}$ denotes the event that consumer $i$ purchases product $k: d_{i k}\left(P_{j}\right)=1$. 
Treatment $T_{i} \in\{0,1\}$ denotes the event that consumer $i$ does not purchase product $j$. In other words $T_{i}=0$ implies $d_{i j}\left(P_{j}\right)=1$ and $T_{i}=1$ implies $d_{i j}\left(P_{j}\right)=0$.

Instrument $Z_{i}=P_{j}$ the price of $j$ induces consumers into not purchasing $j$.

The bottom panel of Table 1 reports the definitions of various treatment effects parameters for the diversion ratio. We note that except under very specific circumstances, these treatment effects estimates (ATE, ATT, ATUT, LATE) will not agree with one another.

The most common threat to the LATE approach is the presence of "defiers" who must be ruled out by the monotonicity assumption. That is less of a concern here, because monotonicity is guaranteed by the "Law of Demand." The second challenge is the plausibility of the exclusion restriction. Here this requires that the utility for $k$ is unaffected by the price of $j$, which is an uncontroversial feature of most discrete choice utility models. ${ }^{13}$

The controversial assumption in Proposition 1 is (e) Random Assignment which enables the price $P_{j}$ to function as an "instrument". What (e) means in words is that the distribution of consumer utilities as a function of price cannot differ with the observed realizations of prices $\left(p_{j}, p_{j}^{\prime}\right)$. This is the usual simultaneity problem in demand and supply that dates back to Working (1927), and would obviously be violated if an unobservable demand shock is correlated with both prices and consumer preferences as in Berry (1994). This is also violated if there is selection that leads to less price sensitive consumers facing higher prices in data including but not limited to cases of price discrimination.

We are cautious to point out that there is no "free lunch" here and that LATE estimates of diversion are not absolved from concerns about price endogeneity. At the same time, assumption (e) does not present a problem for interpreting diversion ratios as treatment effects when we analyze a ceteris paribus change in price in the same way that analyzing the price-elasticity of a demand curve is not complicated by the problems associated with endogeneity of price that arise in estimation of that elasticity.

\subsection{Treatment Effect Heterogeneity}

Different consumers are likely to exhibit different diversion ratios. We show how to decompose a local average treatment effects measure into the underlying heterogeneous distribution and a set of weights in a way that mirrors Heckman and Vytlacil (2005). We begin by re-

\footnotetext{
${ }^{13}$ A potential violation might be a behavioral model with framing effects such as preferences for the "second cheapest" product.
} 
writing the Wald estimator: ${ }^{14}$

$$
\operatorname{Wald}\left(p_{j}, p_{j}^{\prime}, x\right)=\int_{p_{j}}^{p_{j}^{\prime}} D_{j k}\left(p_{s}, x\right) w\left(p_{s}\right) \partial p_{s} \text { with } w\left(p_{s}\right)=\frac{\frac{\partial q_{j}\left(p_{s}, x\right)}{\partial p_{j}}}{\int_{p_{j}}^{p_{j}^{\prime}} \frac{\partial q_{j}\left(p_{t}, x\right)}{\partial p_{j}} \partial p_{t}}
$$

This tells us that the average diversion ratio measured is just the weighted average of diversion ratios at each $D_{j k}\left(p_{s}, x\right)$, where the weights correspond to the consumers who leave $j$ at each price $p_{s}$ as a fraction of all consumers who leave $j$ as the price increases from $\left(p_{j} \rightarrow p_{j}^{\prime}\right)$. All things being equal, as demand for $j$ becomes more elastic, this will concentrate more of the weight $w\left(p_{s}\right)$ towards the diversion ratios measured at prices closer to $p_{j}$. As demand becomes less elastic, the weight is spread more evenly across price increments.

We can further decompose the heterogeneity by observing that at each $p_{s}, D_{j k}\left(p_{s}, x\right)$ implicitly integrates over a heterogeneous distribution of individuals as illustrated in Proposition $1:^{15}$

$$
\begin{aligned}
(5) & =\int_{p_{j}}^{p_{j}^{\prime}} \int D_{j k, i}\left(p_{s}, x\right) w_{i}\left(p_{s}, x\right) \partial p_{s} \partial F_{i} \quad \text { with } w_{i}\left(p_{s}, x\right)=\frac{\left|\frac{\partial q_{i j}\left(p_{s}, x\right)}{\partial p_{j}}\right|}{q_{j}\left(p_{j}, x\right)-q_{j}\left(p_{j}^{\prime}, x\right)} \\
& =\int D_{j k, i}(x) w_{i}\left(p_{j}, p_{j}^{\prime}, x\right) \partial F_{i} \quad \text { with } w_{i}\left(p_{j}, p_{j}^{\prime}, x\right)=\frac{q_{i j}\left(p_{j}, x\right)-q_{i j}\left(p_{j}^{\prime}, x\right)}{q_{j}\left(p_{j}, x\right)-q_{j}\left(p_{j}^{\prime}, x\right)}
\end{aligned}
$$

We've now provided two alternatives for decomposing the heterogeneity in diversion ratios. In (5), we show that the average diversion ratio varies with price, and how Wald estimator/LATE weights diversion ratios at different price increments. In (6), we show that that the Wald estimator/LATE can be decomposed into diversion ratios of individual consumers (which are now independent of price $\left.P_{j}\right)$ and a set of individual-specific weights $w_{i}\left(p_{j}, p_{j}^{\prime}, x\right)$ which depend on realizations of prices $\left(p_{j}, p_{j}^{\prime}\right)$ but not the substitute $k$. These weights determine the (conditional) probability than an individual of type $i$ is a complier under a

\footnotetext{
${ }^{14}$ Observe that $D_{j k}\left(p_{s}, x\right)=\frac{\frac{\partial q_{k}\left(p_{s}, x\right)}{\partial p_{j}}}{\left|\frac{\partial q_{j}\left(p_{s}, x\right)}{\partial p_{j}}\right|}$ so that $D_{j k}\left(p_{s}, x\right)\left|\frac{\partial q_{j}\left(p_{s}, x\right)}{\partial p_{j}}\right|=\frac{\partial q_{k}\left(p_{s}, x\right)}{\partial p_{j}}$. Also notice that the integral in the denominator of the weights is just the change in sales of $j: \int_{p_{j}}^{p_{j}^{\prime}} \frac{\partial q_{j}\left(p_{t}, x\right)}{\partial p_{j}} \partial p_{t}=q_{j}\left(p_{j}, x\right)-$ $q_{j}\left(p_{j}^{\prime}, x\right)$.

${ }^{15}$ This requires the assumptions of Proposition 1 to be satisfied. The second integral arises because at each $p_{s}$ we can write: $D_{j k}\left(p_{s}, x\right)=\int D_{j k, i}\left(p_{s}, x\right) \partial F_{i}$ as the integral over heterogeneous individuals. To exchange the order of integration we need Fubini's Theorem to apply. This is straightforward as $D_{j k}\left(p_{s}, x\right) \geq 0$ and $w_{i}\left(p_{s}, x\right) \geq 0$ everywhere. Less obvious is that $D_{j k, i}(x)=D_{j k, i}\left(p_{s}, x\right)$ for any $p_{s}$. This is demonstrated in Appendix A.2. For discrete choice models we need: $\operatorname{Pr}\left(u_{i k}>\max _{k^{\prime} \in \mathcal{J} \backslash\{j, k\}} u_{i k^{\prime}}\right) \perp p_{j}$ which is guaranteed by the exclusion restriction and the random assignment assumption. In words, the price of $j$ is unrelated to an individual consumer's relative ranking of $k$ and some next best alternative.
} 
particular intervention $\left(p_{j}, p_{j}^{\prime}\right)$.

We know that the different "instruments" measure different LATEs by tracing out different groups of compliers. This means that we can construct some local average measure of diversion ratios with respect to other characteristics. For example, consider a ceteris paribus reduction in quality from $\xi_{j} \rightarrow \xi_{j}^{\prime}$, or an arbitrary characteristic $z_{j} \rightarrow z_{j}^{\prime}$. ${ }^{16}$ This lets us re-write (6) as: ${ }^{17}$

$$
\operatorname{Wald}\left(z_{j}, z_{j}^{\prime}, x\right)=\int D_{j k, i}(x) w_{i}\left(z_{j}, z_{j}^{\prime}, x\right) \partial F_{i} \quad \text { with } w_{i}\left(z_{j}, z_{j}^{\prime}, x\right)=\frac{q_{i j}\left(z_{j}, x\right)-q_{i j}\left(z_{j}^{\prime}, x\right)}{q_{j}\left(z_{j}, x\right)-q_{j}\left(z_{j}^{\prime}, x\right)}
$$

Here we exploit the fact that the individual specific diversion ratios don't vary with price (or even rely on a price change), but rather that the weights vary when we use quality rather than price as the instrument. Any product characteristic $z_{j}$ is valid, so long as it satisfies the monotonicity condition $u_{i j}\left(z_{j}^{\prime}\right) \leq u_{i j}\left(z_{j}\right)$ for all $i$ and any $\left(z_{j}^{\prime}>z_{j}\right)$. ${ }^{18}$ This may seem surprising at first, because we might expect cars to have one elasticity with respect to price, and a different elasticity with respect to fuel economy. What (6) says is that at the individual level there is only one diversion ratio and it is a deep structural parameter that is invariant to whether we change price, quality, or availability. The choice of, or variation in, the instrument simply determines the weights applied to the individual diversion ratios.

This is consistent with results in Heckman (2010); Heckman and Vytlacil (2005); Carneiro et al. (2011) on Marginal Treatment Effects (MTE). Any treatment effect parameter from Table 1 (LATE, ATE, ATT, ATUT, etc.) can be written as the integral of the non-parametric MTE function $\left(D_{j k, i}(x)\right.$ in our case) over some set of weights. As an example, the returns to college attendance at the individual level are fixed and (assumed to be) policy invariant. However, different policy interventions (instruments) such as merit scholarships, affirmative action, or financial aid induce different students to attend college (different compliers) and thus weight the underlying MTEs differently and measure different average effects.

\subsection{Special Case: Second Choice Data}

An important special case is that of second-choice data. In this case, all individuals are treated: $d_{i j}\left(P_{j}\right)=0$ for all $i$. In practice, this could be accomplished in one of several ways:

\footnotetext{
${ }^{16}$ Berry and Haile (2014) exploit the idea that quality functions as "minus price".

${ }^{17}$ Now we treat $p_{j}$ as fixed and contained in $x$.

${ }^{18}$ In a random coefficients logit model, this would require that the sign of $\beta_{i}$ on $z_{j}$ is the same for all individuals. For example, this would rule out cases where some consumers prefer "Mushy" cereal and others do not.
} 
(a) by setting $p_{j}$ equal to the choke price $q_{j}\left(\bar{p}_{j}\right)=0$; (b) by reducing the quality (or some other characteristic) such that no consumers choose $j: q_{j}\left(\underline{\xi_{j}}, x\right)=0$; or (c) eliminating the product $j$ from the choice set $\mathcal{J} \backslash j$. If we apply Proposition 1, we see that:

$$
\operatorname{Wald}\left(p_{j}, \bar{p}_{j}, x\right)=\frac{E\left[d_{i k}\left(\bar{p}_{j}, x\right)\right]-E\left[d_{i k}\left(p_{j}, x\right)\right]}{E\left[d_{i j}\left(p_{j}, x\right)\right]-\underbrace{E\left[d_{i j}\left(\bar{p}_{j}, x\right)\right]}_{=0}}=E\left[D_{j k, i}(x) \mid d_{i j}\left(p_{j}, x\right)=1\right]=\mathrm{ATUT} .
$$

We measure the average diversion ratio for all individuals who would have bought $j$ at the original price $p_{j}$. Since our treatment indicator corresponds to "not buying $j$ ", this is the average treatment on the untreated (ATUT) and is equivalent to the gain in sales by $k$ divided by the lost (original) sales of $j$ at $p_{j} .{ }^{19}$ The instrument we use to obtain second-choice data is irrelevant as all manners of second-choice data identify the ATUT. ${ }^{20}$

If we revisit the example of the UK CMA asking customers: "If this store were to close, where would you shop instead?" and ask whether this is useful for their purposes, we now have a framework to answer that question. The answer depends on whether the ATUT $E\left[D_{j k, i}(x) \mid d_{i j}\left(p_{j}, x\right)=1\right]$ is a good estimate for $D_{j k}\left(P_{j}, x\right)$ at whatever value of $P_{j}$ they are interested in (potentially the pre-merger price). This also provides a specific interpretation for the substitution measured by natural disaster induced hospital closures in Raval et al. (2019).

This also provides a framework to understand the value of second-choice data in parametric models of demand such as Berry et al. (2004) (microBLP). In microBLP, the authors have access to the CAMIP survey data on consumers' second choices. They report finding extra moments from this second-choice data useful in estimating nonlinear (substitution) parameters. Our expression in (8) explains why, these second choices are informative about the average diversion ratios of those surveyed. If the survey is a random sample of buyers of $j$, then it is informative about the ATUT, and "micro-moments" constrain the ATUT of the parametric model to match that from the survey. Additional information on average diversion ratios may be particularly useful for researchers if the corresponding counterfactuals (such as prospective merger evaluation, recovery of implied price-cost margins, or willingness-to-pay

\footnotetext{
${ }^{19}$ As a matter of completeness, the ATT at $p_{j}$ is just $\frac{s_{k}\left(p_{j}\right)}{1-s_{j}\left(p_{j}\right)}$. That is, since being treated is "not buying $j$ " the share of people purchasing $k$ among all non $j$ buyers at $p_{j}$ is merely the observed share. This may look familiar as the rate of substitution from the IIA logit, though no parametric assumptions have been made beyond those in Proposition 1. As we demonstrate later, the IIA logit exhibits constant treatment effects and thus has the property that the ATE $=$ ATT $=$ ATUT.

${ }^{20}$ It is easy to see that $w_{i}$ are equal in $(6)$ and (7) at the "choke price" and "choke quality" $w_{i j}=\frac{q_{i j}(x)}{q_{j}(x)}$.
} 
calculations) depend on accurate measures of diversion.

\subsection{Differences Among Treatment Effects Parameters}

Often researchers want to know whether or not a LATE from the Wald estimator is a good estimate of the ATT, ATE, ATUT, or marginal effect at some $x$. In the typical problem, this depends on the heterogeneity in the individual treatment effects $\left(D_{j k, i}(x)\right.$ in our case) and the selection into treatment. ${ }^{21}$ Consider a second-order Taylor expansion of $q_{k}$ around $p_{j}$, where we define $\Delta p_{j}=p_{j}^{\prime}-p_{j}$ :

$$
\frac{q_{k}\left(p_{j}^{\prime}, x\right)-q_{k}\left(p_{j}, x\right)}{\Delta p_{j}} \approx \frac{\partial q_{k}\left(p_{j}, x\right)}{\partial p_{j}}+\frac{\partial^{2} q_{k}\left(p_{j}, x\right)}{\partial p_{j}^{2}} \Delta p_{j}+O\left(\Delta p_{j}\right)^{2}
$$

The difference between the Wald estimator or LATE, and its limit at $\Delta p_{j} \rightarrow 0$, defined in (4) as $D_{j k}\left(p_{j}, x\right)$, is given by:

$\operatorname{Wald}\left(p_{j}, p_{j}^{\prime}, x\right)-D_{j k}\left(p_{j}, x\right)=\frac{q_{k}\left(p_{j}^{\prime}, x\right)-q_{k}\left(p_{j}, x\right)}{q_{j}\left(p_{j}, x\right)-q_{j}\left(p_{j}^{\prime}, x\right)}-D_{j k}\left(p_{j}, x\right) \approx-\frac{D_{j k}\left(p_{j}, x\right) \frac{\partial^{2} q_{j}}{\partial p_{j}^{2}}+\frac{\partial^{2} q_{k}}{\partial p_{j}^{2}}}{\frac{\partial q_{j}}{\partial p_{j}}+\frac{\partial^{2} q_{j}}{\partial p_{j}^{2}} \Delta p_{j}} \Delta p_{j}$

As one might expect, as $\Delta p_{j}$ becomes larger, the difference between the $\operatorname{Wald}\left(p_{j}, p_{j}^{\prime}, x\right)$ estimator/LATE and $D_{j k}\left(p_{j}, x\right)$ grows. As $p_{j}^{\prime}$ increases, we treat more individuals (and thus reduce the variance of our Wald estimator) but we begin to average over diversion ratios at prices further away from $p_{j}$. This has the effect of changing the weights in (6). What is unique to diversion vis-a-vis other treatment effects applications is that we can link differences in measures of diversion ratios to the underlying properties of demand; specifically to the curvature of demand, which enters the numerator of (10). ${ }^{22}$ This makes it easy to sign the difference or derive bounds for well known demand forms. We discuss several common parametric forms (linear,log-linear, logit, nested logit, and mixed logit) in Appendix A.3.

For some treatment effects parameters, under the discrete-choice assumption (but without additional parametric assumptions beyond those for Proposition 1) we can derive analytic expressions. One example that does not depend on the parametric form is the ATT= $E\left[D_{j k, i}(x) \mid d_{i j}\left(p_{j}, x\right)=0\right]=\frac{s_{k}\left(p_{j}, x\right)}{1-s_{j}\left(p_{j}, x\right)}$. This is just the share of consumers choosing $k$ as a

\footnotetext{
${ }^{21}$ For example, when asking whether the wage effect on the average college attendee is similar to that of the marginal college attendee, this depends on the unobserved underlying distribution of "ability" among other things.

${ }^{22}$ Also notice that we do not need to assume discrete-choice demand for this result.
} 
fraction of all those not choosing $j$. In the case of second-choice data $(A T U T)$, everyone who purchased $j$ at $p_{j}$ is treated, and we weight all individuals by $w_{i}\left(p_{j}, x\right)=s_{i j}\left(p_{j}, x\right)$ (their initial purchase probability for $j$ ), although we cannot say anything at all about $D_{j k, i}(x)$ without additional assumptions. ${ }^{23}$ Meanwhile the $A T E$ (where everyone is treated) is $A T E=E\left[D_{j k, i}(x)\right]=\left(1-s_{j}\right) \cdot A T T+s_{j} \cdot A T U T{ }^{24}$ We expect most practitioners to be interested in the properties of small price changes under the LATE/Wald estimator and its limit $D_{j k}\left(P_{j}, x\right)$, or second-choice data (ATUT), so we don't spend additional attention on the other treatment effects parameters (ATE and ATT).

\subsection{Special Case: Constant Treatment Effects (Diversion Ratios)}

There are some special models for which all of the treatment effects measures coincide, and thus, whether one considers a small price (or quality) change or uses second-choice data, one obtains the same diversion ratio. These are cases where the model exhibits constant treatment effects and all individuals have identical diversion ratios.

Two examples for which the numerator of (10) is equal to zero and produce constant treatment effects (diversion ratios) are: the linear model, for which $\frac{\partial^{2} q_{k}}{\partial p_{j}^{2}}=0$ for all $(j, k)$, and the logit model, which sets the numerator of (10) to zero: $D_{j k}=-\frac{\partial^{2} q_{k}}{\partial p_{j}^{2}} / \frac{\partial^{2} q_{j}}{\partial p_{j}^{2}} \cdot{ }^{25}$ This has implications in both directions. If we assume linear demand or logit demand, we are implicitly assuming that diversion ratios do not vary with price or across individuals. If we treat the diversion ratio as if it were constant, we are implicitly restricting the true demand system to be consistent with linear demand or IIA logit. Researchers should be just as nervous about these restrictions as they would be about constant treatment effects in other contexts such as assuming identical returns to college.

The nested logit model seems like it might have constant diversion ratios (as the product

\footnotetext{
${ }^{23}$ This provides an explanation for the perceived practice of antitrust agencies absent better data: "Assume diversion ratios are proportional to pre-existing market share." This is equivalent to assuming that the ATT is a good estimate of the ATUT (which more generally implies no selection). In the example of college attendance, this is akin to assuming that the returns to college attendance are the same for those who chose to attend and those who chose not to attend. While this resembles the IIA logit, no such parametric restrictions have been made.

${ }^{24}$ The expression is derived from $A T E=\operatorname{Pr}\left(T_{i}=0\right) \cdot A T U T+\operatorname{Pr}\left(T_{i}=1\right) \cdot A T T$ where the probability of being treated (not buying $j$ ) is just $1-s_{i j}\left(p_{j}, x\right)$. Of course $\left(1-s_{j}\right) \times A T T=\frac{s_{k}}{1-s_{j}} \times\left(1-s_{j}\right)=s_{k}$ which is just the share of $k$ and exactly what one would expect.

${ }^{25}$ This is derived in the Appendix A.3. An easier way to see constant diversion under the IIA logit is to observe that $D_{j k, i}=\frac{s_{i k}}{1-s_{i j}}=\frac{s_{k}}{1-s_{j}}$ for all individuals. One might be concerned that this is not the same diversion ratio that one recovers under linear demand, and think that the ATT expression derived under discrete choice $A T T=\frac{s_{k}}{1-s_{j}}$ presents a contradiction. However, as is shown in Jaffe and Weyl (2010), linear demand is inconsistent with discrete choice, and thus these measures are allowed to disagree.
} 
of two IIA logits) but in fact does not. It fails to satisfy the property in (10) which we show in Appendix A.3. This means the diversion ratio from a small change in product characteristics (inclusive of price) is not the same as a diversion ratio obtained from second choice data (ATUT), a fact we have confirmed in simulations. One way to see this is to observe that not all "individuals" have the same diversion ratios, and that diversion ratios vary with the category of the initial product choice. There are different diversion ratios (for small changes in the "index") for products in the same nest: $\frac{s_{k \mid g} Z\left(\sigma, s_{g}\right)}{1-s_{j \mid g} Z\left(\sigma, s_{g}\right)}$ and products in separate nests: $\frac{s_{k}(1-\sigma)}{1-s_{j \mid g} \cdot Z\left(\sigma, s_{g(j)}\right)}$ where $Z\left(\sigma, s_{g}\right)=\left[\sigma+(1-\sigma) s_{g}\right]$.

\subsection{Application to Random Coefficients Logit}

We show how the results in the previous sections can be applied to the workhorse random coefficients logit model that is popular in industrial organization and for merger evaluation in particular (Berry et al., 1995; Nevo, 2001). The random coefficients logit model parametrizes the utility as:

$$
u_{i j}=\beta_{i} z_{j}-\alpha_{i} P_{j}+\xi_{j}+\varepsilon_{i j} \text { with } \varepsilon_{i j}, \sim \text { IID Type } 1 \mathrm{EV}
$$

where $f\left(\beta_{i}, \alpha_{i} ; \theta\right)$ is a parametric distribution known up to a parameter $\theta .{ }^{26}$ This class of models has an "index" so that an "individual" (fixing $\alpha_{i}, \beta_{i}$ but not $\varepsilon_{i}$ ) does not discriminate among changes that make $\left(z_{j}, p_{j}, \xi_{j}\right)$ worse so long as they change the index by an equal number of units. We exploit this index property when computing the integration weights $w_{i j}(x)$. The decomposition from (6) allows us to write any treatment effects parameter for diversion ratios under the random coefficients logit as: ${ }^{27}$

$$
D_{j k}(x)=\int D_{j k, i}(x) w_{i j}(x) \partial F_{i}=\int \frac{s_{i k}(x)}{1-s_{i j}(x)} w_{i j}(x) \partial F_{i}=\int s_{i k}(x) \widetilde{w}_{i j}(x) \partial F_{i}
$$

We make use of several properties. First, when we integrate out over $\varepsilon_{i}$, each indivudal's diversion ratio follows a (different) logit such that $D_{j k, i}(x)=\frac{s_{i k}(x)}{1-s_{i j}(x)} \cdot{ }^{28}$ Consistent with (6) and holding for any discrete-choice model satisfying the assumptions of Proposition 1,

\footnotetext{
${ }^{26}$ The convention in Heckman and Vytlacil (2005) is to consider an "individual agent" as including the error term (here $\varepsilon_{i}$ ). Instead, we follow the random coefficient logit convention an treat an "individual" as a $\left(\beta_{i}, \alpha_{i}\right)$ but integrating over rather than conditioning on $\varepsilon_{i}$. Writing things the other way would prevent us from getting analytic expressions.

${ }^{27}$ Observe that $\widetilde{w}_{i j}(x)=\frac{w_{i j}(x)}{1-s_{i j}(x)}$. We abuse notation and suppress the $\left(p_{j}^{\prime}, p_{j}\right)$ or $\left(\xi_{j}^{\prime}, \xi_{j}\right)$ arguments because a variety of instruments (or none at all - as in second choice data) could be used.

${ }^{28}$ That individual demands follow IIA logit is well-known but a derivation is provided in Appendix A.3.
} 


\begin{tabular}{rcc}
\hline & $w_{i j}(x) \propto$ & $\widetilde{w}_{i j}(x) \propto$ \\
\hline second choice data & $s_{i j}(x)$ & $\frac{s_{i j}(x)}{1-s_{i j}(x)}$ \\
price change $\frac{\partial}{\partial p_{j}}$ & $s_{i j}(x) \cdot\left(1-s_{i j}(x)\right) \cdot\left|\alpha_{i}\right|$ & $s_{i j}(x) \cdot\left|\alpha_{i}\right|$ \\
characteristic change $\frac{\partial}{\partial x_{j}}$ & $s_{i j}(x) \cdot\left(1-s_{i j}(x)\right) \cdot\left|\beta_{i}\right|$ & $s_{i j}(x) \cdot\left|\beta_{i}\right|$ \\
small quality change $\frac{\partial}{\partial \xi_{j}}$ & $s_{i j}(x) \cdot\left(1-s_{i j}(x)\right)$ & $s_{i j}(x)$ \\
finite price change $w_{i}\left(p_{j}, p_{j}^{\prime}, x\right)$ & $\left|s_{i j}\left(p_{j}^{\prime}, x\right)-s_{i j}\left(p_{j}, x\right)\right|$ & $\frac{\left|s_{i j}\left(p_{j}^{\prime}, x\right)-s_{i j}\left(p_{j}, x\right)\right|}{1-s_{i j}(x)}$ \\
finite quality change $w_{i}\left(\xi_{j}, \xi_{j}^{\prime}, x\right)$ & $\left|s_{i j}\left(\xi_{j}^{\prime}, x\right)-s_{i j}\left(\xi_{j}, x\right)\right|$ & $\frac{\left|s_{i j}\left(\xi_{j}^{\prime}, x\right)-s_{i j}\left(\xi_{j}, x\right)\right|}{1-s_{i j}(x)}$ \\
willingness to pay $(\mathrm{WTP})$ & $=\frac{s_{i j}(x)}{\left|\alpha_{i}\right| \cdot s_{i 0}(x)}$ & $\frac{s_{i j}(x)}{\left|\alpha_{i}\right| \cdot s_{i 0}(x)\left(1-s_{i j}(x)\right)}$ \\
\hline
\end{tabular}

Table 2: Weighting of Different Treatment Effects Parameters under RC Logit Note: Weights are used to construct the weighted average diversion measure: $\sum_{i} D_{j k, i}(x) w_{i j}(x)$. Weights must be normalized to integrate to one $\int w_{i j}(x) d F_{i}=1$, but note that $\int \widetilde{w}_{i j}(x) d F_{i} \neq 1$. The weights $w_{i j}(x)$ for the WTP measure are as written (do not integrate to one).

individual diversion ratios don't depend on $P_{j}$. This is because diversion already conditions on individuals not buying good $j .{ }^{29}$ Whether one considers changes of prices, quality, or other characteristics, and whether those changes are large (including second-choice data) or small, affects only weighting and not individual diversion ratios. At the level of the individual $i$, diversion ratios depend only on how $i$ ranks $k$ relative to some alternative $k^{\prime}$.

The second property is that the diversion ratio is always bounded above by $\max _{i} \frac{s_{i k}(x)}{1-s_{i j}(x)}$. The average diversion ratio can never exceed the largest diversion ratio for any individual. In practice this means the individual for whom the combination of $s_{i k}(x)$ and $s_{i j}(x)$ is largest. Unless we see very large individual choice probabilities $s_{i k}(x)$ we should not expect to see very large diversion ratios, even for highly similar products (such as red and blue buses).

The third property, which is specific to the logit family, allows us to rewrite (12) as the integral of two terms: $i$ 's share for the substitute $s_{i k}(x)$, and a re-defined weight $\widetilde{w}_{i j}(x)=$ $\frac{w_{i j}(x)}{1-s_{i j}(x)}$, which depends on $j$. In Table 2 , we compute the corresponding weights for (6) for various treatment effects parameters and instruments. For expositional purposes, we focus on the right hand side of (12) so that we are always integrating the individual's share for $k: s_{i k}(x)$ over the adjusted $\widetilde{w}_{i j}(x)$. We begin by considering a unit change in the index from (11) which we could accomplish by reducing $\xi_{j}$. In this case, all individuals are weighted proportional to their purchase share of the initial good $s_{i j}(x)$, which seems intuitive. If instead, we consider a unit change in a characteristic $z_{j}$ or price $p_{j}$, we concentrate more weight on those individuals more sensitive to the characteristic $\widetilde{w}_{i j}(x) \propto s_{i j}(x)\left|\alpha_{i}\right|$. If all individuals possess the same $\alpha_{i}=\alpha$ then this drops out and these are identical to weights

${ }^{29}$ Note: this is not the same thing as saying that $s_{i j}(x)$ or $s_{i k}(x)$ wouldn't be different at a different value of $\left(p_{j}, p_{k}\right)$; they definitely would be! 
on the marginal change in the quality index $s_{i j}(x)$. Second-choice data instead weights according to $\widetilde{w}_{i j}(x) \propto \frac{s_{i j}(x)}{1-s_{i j}(x)}$. Relative to a small change in the index, it places more weight on individuals with higher initial shares for $s_{i j}(x)$. However, in many cases (such as the BLP automobile example) individual purchase probabilities are small, so that the denominator $1-s_{i j}(x) \approx 1$ and the second-choice weights are nearly identical to those from a marginal change in product quality. ${ }^{30}$ When the share $s_{i j}(x)$ becomes large, the second-choice weights diverge from the marginal quality change weights. In practice, this tends to require a small outside good share (at least for some individuals).

This decomposition highlights the role of random coefficients in diversion ratios. Random coefficients have two effects: the first is to increase dispersion in the share of the substitute $s_{i k}(x)$ (or underlying diversion ratios $\frac{s_{i k}(x)}{1-s_{i j}(x)}$ ), and the second is that when we consider diversion ratios estimated from changes in characteristics with random coefficients it places more weight on the individuals most sensitive to that characteristic. Under the random coefficients logit model, whether or not second choice data (potentially from surveys) produces an estimate similar to that of a small price change depends on how much $s_{i j}(x)\left|\alpha_{i}\right|$ differs from $s_{i j}(x)$ and how correlated $s_{i k}(x)$ is with those weights. We illustrate these properties in our empirical examples.

\subsection{Relationship to Willingness to Pay}

In addition to Upward Pricing Pressure (UPP) and merger simulation, another important object is the Willingness-to-Pay (WTP) measure of Town and Vistnes (2001) and Capps et al. (2003). WTP measures the value of including an option $j$ in a consumer's choice set, and is an important input into the analysis of hospital-insurer networks (e.g., Ho (2006, 2009); Ericson and Starc (2015)) and Nash-in-Nash bargaining between hospitals and insurers (e.g., Gowrisankaran et al. (2015); Ho and Lee (2019)). The WTP measure has also been used outside the hospital-insurer context in the analysis of cable bundles (e.g., Crawford and Yurukoglu (2012)).

We consider a simple version of the WTP measure under the same random coefficients logit model as before. Consumer utility is given by (11) which we write as $u_{i j}=V_{i j}+\varepsilon_{i j}$. There are well known results (Manski and McFadden, 1981) which show the expectation of the maximum has a closed form: $E\left[\max _{k \in \mathcal{J}} u_{i k}\right]=\log \sum_{k \in \mathcal{J}} \exp \left[V_{i k}\right]$. If we follow Capps et al. (2003) or Ho (2006) and ask: "What is the value to consumer $i$ of including $j$ in the

\footnotetext{
${ }^{30}$ This is not the same thing as saying that $s_{j}$ is small, there may still be "individuals" with a high purchase probability for $j$ even if the overall market share $s_{j}$ is small.
} 
choice set?" we obtain: ${ }^{31}$

$$
W T P_{i}(j)=E\left[\max _{k \in \mathcal{J}} u_{i k}\right]-E\left[\max _{k^{\prime} \in \mathcal{J} \backslash j} u_{i k^{\prime}}\right]=\log \left(\sum_{k \in \mathcal{J}} \exp \left[V_{i k}\right]\right)-\log \left(\sum_{k \in \mathcal{J} \backslash j} \exp \left[V_{i k}\right]\right)
$$

We make use of the following relationships: (1) the individual outside good choice probability $s_{i 0}(\mathcal{J}, x)=\frac{1}{\sum_{k \in \mathcal{J}} \exp \left[V_{i k}\right]} ;(2)$ that the outside good choice probability after removing $j$ increases by the individual share of $j$ times the individual diversion ratio from $j$ to the outside good $s_{i 0}(\mathcal{J} \backslash j, x)=s_{i 0}(\mathcal{J}, x)+D_{j 0, i}(x) \cdot s_{i j}(x)$; and (3) for members of the logit family: $D_{j 0, i}(x)=\frac{s_{i 0}(x)}{1-s_{i j}(x)}$. This lets us rewrite (13) as: ${ }^{32}$

$$
\begin{aligned}
& =\log \left(\frac{s_{i 0}(\mathcal{J} \backslash j, x)}{s_{i 0}(\mathcal{J}, x)}\right)=\log \left(1+\frac{D_{j 0, i}(x) s_{i j}(x)}{s_{i 0}(\mathcal{J}, x)}\right)=\log \left(1+\frac{s_{i 0}(\mathcal{J}, x) \cdot s_{i j}(x)}{\left(1-s_{i j}(x)\right) \cdot s_{i 0}(\mathcal{J}, x)}\right) \\
& =\log \left(1+\frac{s_{i j}(x)}{1-s_{i j}(x)}\right) \approx \frac{s_{i j}(x)}{1-s_{i j}(x)}
\end{aligned}
$$

At the individual level, the amount $i$ would pay to have $j$ in his or her choice set is related to the percentage change in the outside good share, or the diversion from $j$ to the outside good $D_{j 0, i}(x)$. This should be intuitive: products that add the most value are those without close substitutes, which draw in consumers from the outside option. Perhaps surprising is that this expression simplifies so that $W T P_{i}(j)$ can be written solely as a function of the individual choice probability for $j, s_{i j}(x)$. This result is of practical relevance because many hospital network papers (e.g., Ho (2006, 2009); Capps et al. (2003)) omit the outside good, and (14) shows us that $W T P_{i}(j)$ requires only an estimate of the individual choice probability $s_{i j}(x)$.

It is common to further aggregate $W T P(i, j)$ across individuals. One convention is to follow Manski and McFadden (1981) and convert difference in utility to money-metric equivalent variation (EV) and aggregate across individuals: ${ }^{33}$

$$
\overline{W T P}(j)=\int \frac{1}{\left|\alpha_{i}\right|} W T P_{i}(j) \partial F_{i} \approx \int \frac{s_{i j}(x)}{\left|\alpha_{i}\right|\left(1-s_{i j}(x)\right)} \partial F_{i}=\int D_{j 0, i}(x) \frac{s_{i j}(x)}{\left|\alpha_{i}\right| \cdot s_{i 0}(\mathcal{J}, x)} \partial F_{i}
$$

\footnotetext{
${ }^{31}$ We simplify by ignoring the probability that consumers face additional ex-ante risk over diagnoses. In this sense, our version more closely resembles Crawford and Yurukoglu (2012).

${ }^{32}$ The approximation arises from the first-order Taylor expansion: $\ln (1+x) \approx x$. This approximation is valid when $s_{i j}$ is small.

${ }^{33}$ Many papers do not identify a heterogeneous price coefficient and thus $\alpha_{i}$ becomes a multiplicative constant in (15).
} 
The last expression in (15) results in the same form as (7), in which we integrate diversion from $j$ to the outside good $\int D_{j 0, i}(x) w_{i j}(x) \partial F_{i}$. The difference is that (15) uses a different set of weights $w_{i j}(x)=\frac{s_{i j}(x)}{\left|\alpha_{i}\right| \cdot s_{i 0}(\mathcal{J}, x)}$. Therefore, we include this as the final example of our decomposition in Table 2. The connection between second-choice data and WTP is that measures of diversion that use second-choice data integrate $s_{i k}(x)$ over $\widetilde{w}_{i j}(x)=\frac{s_{i j}(x)}{1-s_{i j}(x)}$, while in the absence of heterogeneous tastes for price, WTP integrates a constant 1 over the same set of weights $\widetilde{w}_{i j}(x)=\frac{s_{i j}(x)}{1-s_{i j}(x)}$.

\section{Applications using Nevo (2000) and Berry, Levinsohn, and Pakes (1999)}

To illustrate our theoretical results on diversion ratios, we use the two well-known examples from Nevo (2000b) and Berry et al. (1999). The data in Nevo (2000b) are simulated fake data meant to mimic the cereal industry from Nevo (2001), and consist of $T=94$ markets, $J=24$ products, and $N=2,256$ observations. ${ }^{34}$ The Berry et al. (1999) data are annual national aggregate automobile sales by make and model for $T=21$ markets (each market is a year),with up to $J=150$ products per market and a total of $N=2,217$ observations. An advantage of the BLP data is that product names are attached, which help to interpret results. ${ }^{35}$

The specifications of utility in the two models are given by:

$$
\begin{aligned}
& u_{i j t}^{\mathrm{BLP}}=x_{j t} \underbrace{\left(\bar{\beta}+\Sigma \cdot \nu_{i}\right)}_{\beta_{i t}}-\alpha \cdot \frac{p_{j t}}{\mathrm{y}_{i t}}+\xi_{j t}+\varepsilon_{i j t} \\
& u_{i j t}^{\mathrm{Nevo}}=x_{j t} \underbrace{\left(\bar{\beta}+\Sigma \cdot \nu_{i}+\Pi \cdot d_{i t}\right)}_{\beta_{i t}}+d_{j}+\Delta \xi_{j t}+\varepsilon_{i j t}
\end{aligned}
$$

The main difference between the two specifications is that Nevo (2000b) contains product fixed effects for each of the 24 brands $d_{j}$, and allows for interactions between household income and presence of children with tastes for product characteristics (the $\Pi$ parameters). In the Berry et al. (1999) example price is interacted with $1 / y_{i t}$ where $y_{i t}$ is a draw from a lognormal distribution of income. ${ }^{36}$

We estimate these parameters using the PyBLP software package of Conlon and Gort-

\footnotetext{
${ }^{34}$ These data are posted online by the author, and are not the actual data used in Nevo (2001), which are proprietary.

${ }^{35}$ This information is not available for the simulated Nevo (2000b) data.

${ }^{36}$ This is better behaved than $\alpha \cdot \log \left(y_{i}-p_{j t}\right)$ from Berry et al. (1995). In estimation, Berry et al. (1999) also includes moment restrictions derived from an oligopolistic price-setting supply-side, which we include in estimation but do not report.
} 
maker (2020). In doing so, we implement the recommended "best practices" which involve calculating the nonlinear approximation to the optimal instruments. For the Nevo (2000b) example, we use the same 20 simulation draws provided in the original data package. For the Berry et al. (1999) example, the original draws are not available and we use 500 Halton draws. In addition to the baseline "best practices" estimates for each model, we consider three modified models in order to highlight how restrictions on parametric models are related to diversion ratios. In the first case, we eliminate all heterogeneous tastes for price $\pi_{p}=\sigma_{p}=0$. In the second case we eliminate all heterogeneous tastes for the constant term $\sigma_{0}=\pi_{0}=0$ (which governs "inside" vs. "outside" good substitution). We consider these two examples because many researchers consider these forms of heterogeneity to be among the most important to capture when modeling demand. In the final case, we rescale the market shares for all "inside" goods by a factor of three. This is meant to capture researcher uncertainty about the overall size of the market. In the Nevo (2000b) case we multiply $s_{j t} \cdot \frac{1}{3}$ and in the Berry et al. (1999) case we multiply $s_{j t} \cdot 3 \cdot{ }^{37}$

We report the parameter estimates in Table $3 .^{38}$ The top panel reports estimates for the Berry et al. (1999) example. Best practices estimates are reported in the first column. The second column reports estimates that omit heterogeneity on the constant term, which are similar. In the third column, we report estimates that omit heterogeneity on price, which differ significantly from the estimates in the first two columns. The last column rescales the market shares of all inside products, simulating a change in the assumed market size. As expected, the parameter estimates are sensitive to this change too. In the bottom panel, we perform the same comparisons for the Nevo (2001) example. In this case, we find that omitting heterogeneity on the price term gives estimates quite similar to 'best practices,' while omitting heterogeneity on the constant term and rescaling shares both lead to significantly different estimates.

For later comparisons, we also include a simple nested-logit model with all 'inside' products in a single nest. The nested-logit model offers a helpful comparison because, unlike the plain logit, it allows for a parameter that governs diversion to the outside good. Accordingly, the nested-logit is often used by researchers or antitrust agencies to provide a "first cut," or to model demand under time and/or data constraints. There are no random coefficients

\footnotetext{
${ }^{37}$ In the BLP case this can be interpreted as people look for a new car at most once every three years instead of every year. In the Nevo case this effectively triples the potential number of servings (breakfast, lunch, and dinner, instead of breakfast only), that a household could consume each period.

${ }^{38}$ We only present the nonlinear parameters here. For the mean value of product characteristics consult Table B.1 in Appendix B.
} 
to report for the nested-logit model, so we do not include it in Table 3. The only relevant parameter is the nesting parameter. In the Berry et al. (1999) example, we estimate the nesting parameter to be $\rho \approx 0.78$. For the Nevo (2001) example, we cannot estimate a nesting parameter because the fake data have the same number of products in all markets, leaving us without an instrument for the nesting parameter, or any necessary variation for estimation. Instead, we calibrate the nesting parameter to match the outside good diversion $(\rho=0.375) \cdot{ }^{39}$

In Table 4 we explore the relationship between parametric restrictions on random coefficients logit models and the resulting effects on elasticities and diversion ratios. In both the Nevo and BLP examples, the median own elasticity is relatively stable across random coefficients specifications. The BLP and Nevo examples again struggle with different sets of restrictions, suggesting the models capture important sources of heterogeneity through different sets of parameters. Overall, the BLP example looks substantially different when we restrict heterogeneity on prices, and the Nevo example looks substantially different when we omit heterogeneous tastes for the constant, which governs inside vs. outside good substitution. Absent the key dimension of heterogeneity, diversion to the outside good increases from around $20 \%$ to around $89 \%$ in the BLP case, and from $33 \%$ to around $42 \%$ in the Nevo case. We see a similar, though less interpretable effect on the aggregate elasticity in both examples. The challenges with using aggregate elasticity as a diagnostic are highlighted when we rescale the shares. In the BLP example, we effectively triple the share of inside goods, which reduces outside good diversion to around 16\%; however, the aggregate elasticity doubles (from roughly $9 \%$ to $18 \%$ ) because the outside good share has declined. In the Nevo example, we effectively triple the share of the outside good, and thus outside good diversion increases from around $33 \%$ to $78 \%$, while the aggregate elasticity falls from about $53 \%$ to $38 \%$ (even though more consumers are diverted to the outside option). This suggests that outside good diversion is a more useful diagnostic than the aggregate elasticity. In general, the lack of stability in the outside good diversion (and aggregate elasticity) across specifications suggests this might be helped by additional (micro) moments or second-choice data. $^{40}$

We also report (sales-weighted) substitution to the top 5 substitutes for each product.

\footnotetext{
${ }^{39}$ This calibration is meant to represent a "best case" scenario for nested logit, or what we might hope to estimate if we had access to micro-moments or second choice data.

${ }^{40}$ As an example, consider demand for distilled spirits as in Conlon and Rao (2019) or Miravete et al. (2018). We might also have quasi-experimental estimates (e.g., from a tax change on the total quantity sold within a particular state), and could use this as additional information.
} 


\begin{tabular}{|c|c|c|c|c|}
\hline & Best Practices & $\Sigma_{\mathrm{cons}}=\pi_{\mathrm{cons}}=0$ & $\Sigma_{p}=\pi_{p}=0$ & Rescaled Shares \\
\hline \multicolumn{5}{|l|}{ BLP } \\
\hline price/inc & $\begin{array}{c}-51.254 \\
(5.847)\end{array}$ & $\begin{array}{l}-49.175 \\
(7.104)\end{array}$ & $\begin{array}{l}-0.355 \\
(0.030)\end{array}$ & $\begin{array}{l}-11.277 \\
(2.218)\end{array}$ \\
\hline$\sigma_{\mathrm{cons}}$ & $\begin{array}{l}2.052 \\
(1.111)\end{array}$ & $\begin{array}{l}- \\
-\end{array}$ & $\begin{array}{l}0.024 \\
(35.915)\end{array}$ & $\begin{array}{l}3.159 \\
(1.364)\end{array}$ \\
\hline$\sigma_{\mathrm{HP} / \text { weight }}$ & $\begin{array}{l}1.785 \\
(2.061)\end{array}$ & $\begin{array}{l}2.661 \\
(1.258)\end{array}$ & $\begin{array}{l}0.097 \\
(33.495)\end{array}$ & $\begin{array}{l}1.257 \\
(2.257)\end{array}$ \\
\hline$\sigma_{\text {air }}$ & $\begin{array}{l}1.899 \\
(0.439)\end{array}$ & $\begin{array}{l}1.135 \\
(0.522)\end{array}$ & $\begin{array}{l}0.080 \\
(133.351)\end{array}$ & $\begin{array}{l}1.408 \\
(0.445)\end{array}$ \\
\hline$\sigma_{\mathrm{MP} \$}$ & $\begin{array}{l}0.708 \\
(0.184)\end{array}$ & $\begin{array}{l}0.157 \\
(0.223)\end{array}$ & $\begin{array}{l}0.003 \\
(14.096)\end{array}$ & $\begin{array}{l}0.151 \\
(0.361)\end{array}$ \\
\hline$\sigma_{\text {size }}$ & $\begin{array}{l}1.126 \\
(0.917)\end{array}$ & $\begin{array}{l}1.554 \\
(0.736)\end{array}$ & $\begin{array}{l}0.012 \\
(29.555)\end{array}$ & $\begin{array}{l}0.261 \\
(2.405)\end{array}$ \\
\hline \multicolumn{5}{|l|}{ Nevo } \\
\hline$\alpha_{\text {price }}$ & $\begin{array}{c}-31.125 \\
(4.700)\end{array}$ & $\begin{array}{l}-42.642 \\
(3.627)\end{array}$ & $\begin{array}{c}-30.939 \\
(0.913)\end{array}$ & $\begin{array}{l}-36.280 \\
(2.507)\end{array}$ \\
\hline$\sigma_{\text {price }}$ & $\begin{array}{l}2.983 \\
(0.650)\end{array}$ & $\begin{array}{l}1.362 \\
(0.741)\end{array}$ & $\begin{array}{l}- \\
-\end{array}$ & $\begin{array}{l}2.314 \\
(0.537)\end{array}$ \\
\hline$\sigma_{\mathrm{cons}}$ & $\begin{array}{l}0.217 \\
(0.078)\end{array}$ & $\begin{array}{l}- \\
-\end{array}$ & $\begin{array}{l}0.246 \\
(0.079)\end{array}$ & $\begin{array}{l}0.016 \\
(0.070)\end{array}$ \\
\hline$\sigma_{\text {sugar }}$ & $\begin{array}{l}0.027 \\
(0.007)\end{array}$ & $\begin{array}{l}0.055 \\
(0.012)\end{array}$ & $\begin{array}{l}0.055 \\
(0.012)\end{array}$ & $\begin{array}{l}0.028 \\
(0.007)\end{array}$ \\
\hline$\sigma_{\text {mushy }}$ & $\begin{array}{l}0.294 \\
(0.101)\end{array}$ & $\begin{array}{l}0.720 \\
(0.339)\end{array}$ & $\begin{array}{l}0.835 \\
(0.302)\end{array}$ & $\begin{array}{l}0.172 \\
(0.089)\end{array}$ \\
\hline$\pi_{\text {price } \times \text { inc }}$ & $\begin{array}{l}92.746 \\
(89.324)\end{array}$ & $\begin{array}{l}49.645 \\
(66.938)\end{array}$ & $\begin{array}{l}- \\
-\end{array}$ & $\begin{array}{l}214.812 \\
(40.954)\end{array}$ \\
\hline$\pi_{\text {price } \times \text { inc }^{2}}$ & $\begin{array}{l}-5.266 \\
(4.621)\end{array}$ & $\begin{array}{l}-1.535 \\
(3.492)\end{array}$ & $\begin{array}{l}- \\
-\end{array}$ & $\begin{array}{l}-11.596 \\
(2.143)\end{array}$ \\
\hline$\pi_{\text {price }} \times$ kids & $\begin{array}{l}4.056 \\
(2.260)\end{array}$ & $\begin{array}{l}0.186 \\
(2.511)\end{array}$ & $\begin{array}{l}- \\
-\end{array}$ & $\begin{array}{l}3.537 \\
(2.021)\end{array}$ \\
\hline$\pi_{\text {cons } \times \text { inc }}$ & $\begin{array}{l}6.043 \\
(0.538)\end{array}$ & $\begin{array}{l}- \\
- \\
-\end{array}$ & $\begin{array}{l}4.819 \\
(0.357)\end{array}$ & $\begin{array}{l}4.071 \\
(0.435)\end{array}$ \\
\hline$\pi_{\text {cons } \times \text { age }}$ & $\begin{array}{l}0.161 \\
(0.203)\end{array}$ & $\begin{array}{l}- \\
-\end{array}$ & $\begin{array}{l}-0.049 \\
(0.200)\end{array}$ & $\begin{array}{l}0.018 \\
(0.194)\end{array}$ \\
\hline$\pi_{\text {sugar } \times \text { inc }}$ & $\begin{array}{l}-0.310 \\
(0.035)\end{array}$ & $\begin{array}{l}-0.088 \\
(0.030)\end{array}$ & $\begin{array}{l}-0.245 \\
(0.023)\end{array}$ & $\begin{array}{l}-0.287 \\
(0.035)\end{array}$ \\
\hline$\pi_{\text {sugar } \times \text { age }}$ & $\begin{array}{l}0.049 \\
(0.013)\end{array}$ & $\begin{array}{l}0.023 \\
(0.016)\end{array}$ & $\begin{array}{l}0.036 \\
(0.016)\end{array}$ & $\begin{array}{l}0.046 \\
(0.015)\end{array}$ \\
\hline$\pi_{\text {mushy } \times \text { inc }}$ & $\begin{array}{l}0.982 \\
(0.279)\end{array}$ & $\begin{array}{l}1.193 \\
(0.310)\end{array}$ & $\begin{array}{l}0.741 \\
(0.261)\end{array}$ & $\begin{array}{l}0.805 \\
(0.266)\end{array}$ \\
\hline$\pi_{\text {mushy } \times \text { age }}$ & $\begin{array}{l}-0.537 \\
(0.181)\end{array}$ & $\begin{array}{l}-0.029 \\
(0.237)\end{array}$ & $\begin{array}{l}-0.176 \\
(0.230)\end{array}$ & $\begin{array}{l}-0.508 \\
(0.180)\end{array}$ \\
\hline
\end{tabular}

Table 3: Parameter Estimates for Berry et al. (1999) and Nevo (2000b).

Best practices refers to estimates with optimal instruments. See Conlon and Gortmaker (2020) for more details.

BLP example uses 500 Halton draws to approximate the numerical integral and includes supply side.

Nevo (2000b) example uses the same 20 point distribution of heterogeneity included with the (simulated) data.

Rescaled Shares takes $s_{j} \times 3$ for BLP and $s_{j} \times \frac{1}{3}$ for Nevo. 
The badly misspecified models (lacking price heterogeneity for BLP, or heterogeneity on the constant term for Nevo) understate substitution to the closest substitutes relative to the baseline model. Rescaling the inside shares for BLP leads to a slight increase in diversion to the best substitutes, and rescaling the outside share for Nevo leads to a substantial reduction in diversion to the closest substitutes, from about $40 \%$ to $13 \%$. In both cases these effects appear to be related to the change in outside good diversion. Markups (shown in (1) to be largely a function of own-elasticity and diversion to products of the same owner) appear to be more stable, but are still sensitive to outside good diversion, with more outside good diversion being associated with lower markups. As we showed in (15), consumer surplus is largely a function of three things: own share $s_{i j}(x)$, diversion to the outside good $D_{j 0, i}(x)$, and price sensitivity $\alpha_{i}$. Thus, it should be unsurprising that specifications that estimate different outside good diversion, also give wildly different consumer surplus calculations (as does the BLP model with heterogeneous tastes for price). ${ }^{41}$

Although the nested-logit model matches the outside good diversion reasonably well in both examples (by construction in the Nevo example), they do not capture the full extent of diversion to the top 5 substitutes, because no parameters are left to explain similarities among pairs of products. ${ }^{42}$ This also highlights that for these two examples, the "flexibility" of the random coefficients specification is largely about capturing the inside/outside good diversion margin rather than similarities across pairs of products, which even for the closest substitutes are within 10\% between the nested logit and baseline specifications.

\subsection{Differences Among Treatment Effects Estimates}

As we discussed in Section 3.5, different "instruments" will recover different average measures of diversion ratios. An important question is how different these measures are from one another. For example, if the UK CMA were interested in the effect of a horizontal merger among retail supermarkets and surveyed potential customers asking about their second choice (e.g., "If this store were to close, where would you shop?"), one might want to know the difference between diversion estimated from a small price change $D_{j k}\left(p_{j}, x\right)$ and diversion estimated from the second-choice survey. As another example, suppose that we wanted to

\footnotetext{
${ }^{41}$ We need to be careful about consumer surplus comparisons because comparing utilities across specifications is not possible. However, these CS calculations are money-metric in that $C S_{i}(x)$ is scaled by $\frac{1}{\alpha_{i}}$ for each individual and then market averages are reported.

${ }^{42}$ The BLP nested logit has an additional problem because we omit the supply side. This leads to less elastic estimates of demand, which also impact markups and consumer surplus. Estimating the nested logit with all products in one nest and the same supply-side restrictions used by Berry et al. (1999), gives an estimate of $\rho \approx 1.4$, which is not necessarily consistent with random utility maximization. (See McFadden and Train (2000).)
} 


\begin{tabular}{|c|c|c|c|c|c|}
\hline & Best Practices & $\Sigma_{\mathrm{cons}}=\pi_{\mathrm{cons}}=0$ & $\Sigma_{p}=\pi_{p}=0$ & Rescaled Shares & Nested Logit \\
\hline \multicolumn{6}{|l|}{ BLP } \\
\hline Median Own-Elasticity & -3.811 & -3.481 & -3.098 & -2.632 & -1.600 \\
\hline Median Aggregate Elasticity & -0.096 & -0.095 & -0.258 & -0.178 & -0.033 \\
\hline Median Outside-Good Diversion & 0.201 & 0.227 & 0.892 & 0.163 & 0.197 \\
\hline Mean Top 5 Diversion & 0.182 & 0.165 & 0.022 & 0.191 & 0.165 \\
\hline Mean Markup & 0.334 & 0.359 & 0.385 & 0.468 & 0.936 \\
\hline Median Consumer Surplus & 2.071 & 2.005 & 0.323 & 14.726 & 2.827 \\
\hline \multicolumn{6}{|l|}{ Nevo } \\
\hline Median Own-Elasticity & -3.654 & -3.735 & -3.686 & -3.622 & -3.995 \\
\hline Median Aggregate Elasticity & -0.534 & -0.683 & -0.558 & -0.383 & -0.584 \\
\hline Median Outside-Good Diversion & 0.329 & 0.418 & 0.341 & 0.780 & 0.342 \\
\hline Mean Top 5 Diversion & 0.406 & 0.334 & 0.392 & 0.129 & 0.385 \\
\hline Mean Markup & 0.402 & 0.384 & 0.402 & 0.324 & 0.363 \\
\hline Median Consumer Surplus & 2.946 & 3.750 & 3.218 & 0.628 & 3.011 \\
\hline
\end{tabular}

Table 4: Comparison of Diversion and Elasticities for Berry et al. (1999) and Nevo (2000b).

Mean markup and diversion are sales-weighted.

Nested Logit (BLP): all products in single nest and estimates $\rho=0.78$.

Nested Logit (Nevo): all products in single nest and calibrates $\rho=0.375$ to match outside good diversion.

know how consumers might respond to a reduction in the quality of cellular phone plans, but we only had information from "number porting" data during a period in which consumer switching was driven largely by price cuts from Sprint and T-Mobile. ${ }^{43}$

In Section 3.7 and Table 2 we derived expressions for how these different interventions weighted different groups of individuals. Here we illustrate the implications of these different weights for the BLP and Nevo examples under the baseline specifications from the prior section. In our first exercise, we compare the diversion ratios obtained for every product in every market under the various "instruments" or interventions (small price changes, small quality changes, second-choice data, etc.).

In Table 5, we examine substitution to the best substitute for each product and to the outside good. For the BLP example, we measure diversion ratios for the best substitute for each vehicle, considering a small change in price or quality, or a product removal. All three random-coefficient measures are similar for the best substitute. We predict somewhat less substitution to each product's closest substitute with the nested-logit specification. This is expected, because the nested-logit model lacks parameters that make a Camry similar to an Accord. The plain logit performs quite poorly, as it cannot properly capture diversion

\footnotetext{
${ }^{43}$ It is true that if we had a fully specified model parametric demand model we could answer these questions. Though in the first example, it seems unlikely that the CMA could estimate a price parameter or elasticity given the available data, and in the second example it might be challenging to estimate preferences for "quality" if it were subsumed into provider intercepts.
} 


\begin{tabular}{lrrrrr}
\hline & $D_{j k}(p)$ & Small Quality Change & Second Choice & Logit & Nested Logit $D_{j k}(p)$ \\
\hline BLP & & & & \\
\hline Med $\left(D_{j k}\right)$ & 4.53 & 4.62 & 4.63 & 0.46 & 3.85 \\
Mean $\left(D_{j k}\right)$ & 5.11 & 5.30 & 5.33 & 0.53 & 3.97 \\
\% Correct & 100.00 & 97.29 & 97.29 & 95.58 & 95.58 \\
\hline $\operatorname{Med}\left(D_{j 0}\right)$ & 20.08 & 14.40 & 14.33 & 89.26 & 19.66 \\
$\operatorname{Mean}\left(D_{j 0}\right)$ & 20.29 & 14.95 & 14.88 & 89.36 & 19.71 \\
\hline Nevo & & & & 12.54 \\
\hline $\operatorname{Med}\left(D_{j k}\right)$ & 13.03 & & & & 13.82 \\
Mean $\left(D_{j k}\right)$ & 15.29 & 12.83 & 14.90 & 8.89 & 34.23 \\
\% Correct & 100.00 & 14.79 & 94.46 & 64.23 & 34.20 \\
\hline $\operatorname{Med}\left(D_{j 0}\right)$ & 32.91 & 94.33 & 34.00 & 54.43 & 33.73 \\
Mean $\left(D_{j 0}\right)$ & 32.88 & 34.13 & 33.85 & 53.46 & \\
\hline
\end{tabular}

Table 5: Diversion to Best Substitute and Outside Good

The first panel in each set reports diversion to each product-market pair's best substitute. The second panel in each set reports diversion to the outside good.

\begin{tabular}{lrrrr}
\hline & BLP & \multicolumn{2}{c}{ Nevo } \\
\hline & $\operatorname{med}(|y-x|)$ & $\operatorname{mean}(y-x)$ & $\operatorname{med}(|y-x|)$ & $\operatorname{mean}(y-x)$ \\
\hline \hline Top 5 Substitutes & & & & \\
\hline Small Quality Change & 10.57 & 2.49 & 3.66 & -2.73 \\
Second Choice & 10.47 & 2.81 & 3.34 & -2.03 \\
Logit & 19.53 & -22.38 & 38.80 & -44.41 \\
Nested Logit $D_{j k}(p)$ & 19.06 & -6.48 & 19.06 & -6.48 \\
\hline All Products & & & & \\
\hline Small Quality Change & 21.25 & 27.94 & 4.92 & -0.55 \\
Second Choice & 21.39 & 27.85 & 4.63 & -0.64 \\
Logit & 191.18 & -170.71 & 38.64 & -29.47 \\
Nested Logit $D_{j k}(p)$ & 33.71 & 32.73 & 32.22 & 8.46 \\
\hline Outside Good & \multicolumn{5}{c}{} \\
\hline Small Quality Change & 32.62 & -31.63 & 3.86 & 5.40 \\
Second Choice & 33.03 & -32.19 & 3.25 & 4.35 \\
Logit & 149.38 & 168.63 & 44.63 & 58.46 \\
Nested Logit $D_{j k}(p)$ & 39.28 & 17.46 & 29.95 & 12.33 \\
\hline
\end{tabular}

Table 6: Relative \% Difference in Diversion Measures

Baseline is small-price change measure: $D_{j k}\left(p_{j}\right)$.

Observations are product-market pairs and are equally weighted.

Median Absolute Deviation med $(|y-x|)$ and "Bias" $E[y-x]$ where $(x, y)$ are log-diversion. 
to the outside good, which in the case of the BLP data is extremely large. ${ }^{44}$ Diversion to the outside good is larger when considering a small price change (around 20\%) than when considering a change in quality or second choice data (around 15\%). This can be explained by differences in the weights in Table 2 , and theoretically could go in either direction. The only difference between a marginal change in quality and second-choice data is a factor of $\frac{1}{1-s_{i j}(x)}$, but for most products $\frac{1}{1-s_{i j}(x)} \approx 1$ because the outside share is so large (often greater than $90 \%$ ). However, responses to small changes in prices are substantially different because they place additional weight on more price sensitive consumers (large $\left|\alpha_{i}\right|$ ). In the BLP example, price sensitivity is quite dispersed because it tracks income $\left(\alpha_{i}=\frac{\alpha}{\text { income }_{i}}\right)$, and low-income consumers have much larger outside good shares $s_{i 0}(x)$. We illustrate our decomposition of individual diversion measures and weights in more detail in Section 4.2.

We see a different pattern with the Nevo example. Here measures of diversion to the best substitute and diversion to the outside good are less sensitive to the particular weighting scheme that is used. This is despite the fact that there is still quite a bit of heterogeneity in the price sensitivity $\alpha_{i}$ as demonstrated by the magnitude of $\sigma_{\text {price }}$ and $\pi_{\text {price } \times \text { inc }}$ and $\pi_{\text {price } \times \text { inc }^{2}}$ from Table 3. ${ }^{45}$ This result is due to the fact that there is not as much heterogeneity in the underlying individual diversion ratios $D_{j k, i}(x)$ as demonstrated by two features of this market. First, the diversion ratios to each product's best substitute are similar between the nested-logit model, which predicts substitution proportional to share, and the randomcoefficients model under any intervention. Second, beyond two discrete types of cereal (i.e., mushy and non-mushy), the extent of heterogeneous preferences for other characteristics in the Nevo application (i.e., sugar) is not very large.

This last point is highlighted by the "\% Correct," which reports the fraction of observations for which each model predicts the same best substitute as the small-price change measure of diversion $D_{j k}\left(p_{j}, x\right)$. For the Nevo example, the three interventions identify the same best substitute at least $94 \%$ of the time, while the nested-logit model does less well, identifying the top substitute only $64 \%$ of the time. ${ }^{46}$ In the BLP example, nearly all interventions and specifications predict the same substitute for all products; thus, even the plain logit agrees with $D_{j k}\left(p_{j}, x\right) 95 \%$ of the time. What is perhaps disappointing for the BLP example is that diversion ratios to best substitutes are generally quite small (around 5\%). This is in part driven by the larger number of products, but also suggests the possibility

\footnotetext{
${ }^{44}$ Berry et al. (1999) defines the market as every household in the United States purchasing up to one automobile each year.

${ }^{45}$ We provide histograms of $\alpha_{i}$ for both BLP and Nevo in Figure B.1 of the Appendix.

${ }^{46}$ This is mostly because the nested-logit model cannot distinguish between mushy and non-mushy cereal.
} 
that even more random coefficients or demographic interactions might have been helpful.

In Table 6, we provide a standard econometric comparison among the different diversion measures. We use the small-price change case as our baseline, and compare (on the log-scale) the discrepancies between average diversion ratios measured using small quality changes, second-choice data, logit, and nested-logit models. We use two metrics for our comparison, the mean difference (bias), and the median absolute deviation (dispersion). ${ }^{47}$ For the BLP example, we find that diversion to the top 5 substitutes from alternative "instruments" (second-choice data and small quality changes) are off by around $10 \%$ on average with some being overstated and others being understated when compared to the small price change measure. As in Table 5 there are substantial discrepancies among the different "instruments" for the BLP data with second-choice and small-quality changes predicting around $30 \%$ less diversion to the outside good than a small-price change, and around $27 \%$ more diversion to "all inside goods." The results are much more similar in the Nevo example, with the various random coefficients diversion measures all within around $5 \%$ of the smallprice change predictions. As expected, the nested-logit model under-predicts substitution to the top substitutes and over-predicts substitution to "the field" of all inside goods. ${ }^{48}$

This raises the question: why do we see substantial discrepancies in diversion measured using small-price changes versus small changes in quality or second-choice data in the BLP data, but not in the Nevo (fake) data?

\subsection{Decomposition of Diversion Measures}

In this section we demonstrate our decomposition from (7) which shows that we can decompose any measure of diversion ratios (second-choice data, small price changes, small quality changes) into two components: (1) an individual diversion measure $D_{j k, i}(x)$ that does not depend on the policy instrument; and (2) a set of weights $w_{i j}\left(x, z_{j}, z_{j}^{\prime}\right)$ that depend on the policy change, but do not depend on the identity of the substitute. The individual treatment effects (diversion ratios) are considered structural parameters in the sense that they are policy invariant aspects of consumer preferences, which do not depend on whether we measure diversion by changing price or product quality (or by how much).

This policy invariance has led objects like $D_{j k, i}(x)$ to be described as marginal treatment effects in the language of Heckman and Vytlacil (2005), as they can be integrated over different sets of weights to calculate the well-known treatment effects parameters (ATE,

\footnotetext{
${ }^{47}$ In Appendix B we provide a pairwise correlation matrix for these measures.

${ }^{48}$ The nested logit does a good job matching the sales-weighted outside good diversion in Table 5 .
} 
ATT, ATUT, LATE, etc.). ${ }^{49}$ To illustrate this connection, we present two sets of plots in Figure 1 and Figure 2. These are meant to parallel those in Carneiro et al. (2011), which plot the $\operatorname{MTE}(x)$ against the propensity score (i.e., the probability that an individual is "treated").

In the first panel of each plot, we compute $D_{j k, i}(x)=\frac{s_{i k}(x)}{1-s_{i j}(x)}$ for each simulated "individual" in the Berry et al. (1999) model. We plot this against each individual's purchase probability for product $j, s_{i j}$, because our treatment is "not buying $j$." Figure 1 plots diversion measures from a Honda Accord to two substitutes: Toyota Camry and Cadillac DeVille. The plots reveal a large number of blue dots near the origin, representing individuals who are unlikely to purchase either an Accord or a Camry. Indeed, most consumers in the BLP data don't purchase any automobile at all. As we move right across the graph, we find that individuals who are more likely to purchase an Accord are also more likely to purchase a Camry. To help visualize this relationship, we provide a local linear smoothed line in blue, which is clearly increasing. This increasing relationship tells us about the covariance between the individual diversion measures and their weights in (6), and indicates that the products are close substitutes beyond what would be predicted by share alone. What is also interesting is that although these products are "close substitutes" even at the individual level, the highest diversion ratio we observe is around $8 \%$.

As a contrasting case, in green in Figure 1 we conduct the same exercise but with the bestselling luxury car (the Cadillac DeVille) as the substitute instead. There are some individuals with diversion ratios as high as $14 \%$ between the Accord and the DeVille. However, because those individuals are on the left of the graph, these are individuals who are unlikely to buy the Accord in the first place (presumably because they are luxury car buyers, rather than economy car buyers). Although it is harder to see because of the large number of non-car buyers towards the bottom of the figure, the smoothed green line slopes downwards, suggesting that individuals who really like the Accord are less likely to switch to the DeVille.

In the second panel of Figure 1 we plot a histogram for two different sets of weights across individuals. In blue, we plot the set of weights corresponding to a small price change $w_{i j}(x)=\left|\alpha_{i}\right| s_{i j}(x)\left(1-s_{i j}(x)\right)$, while in red we plot the weights corresponding to secondchoice data (or product removal) $w_{i j}(x)=s_{i j}(x)$. For the most part, the resulting histogram is purple, suggesting that the weights are largely similar for the two interventions. However, we see that second-choice weights tend to place slightly more weight on "more likely" Accord buyers (towards the right of the figure) than the small price change weights do.

\footnotetext{
${ }^{49}$ This is demonstrated in (7).
} 


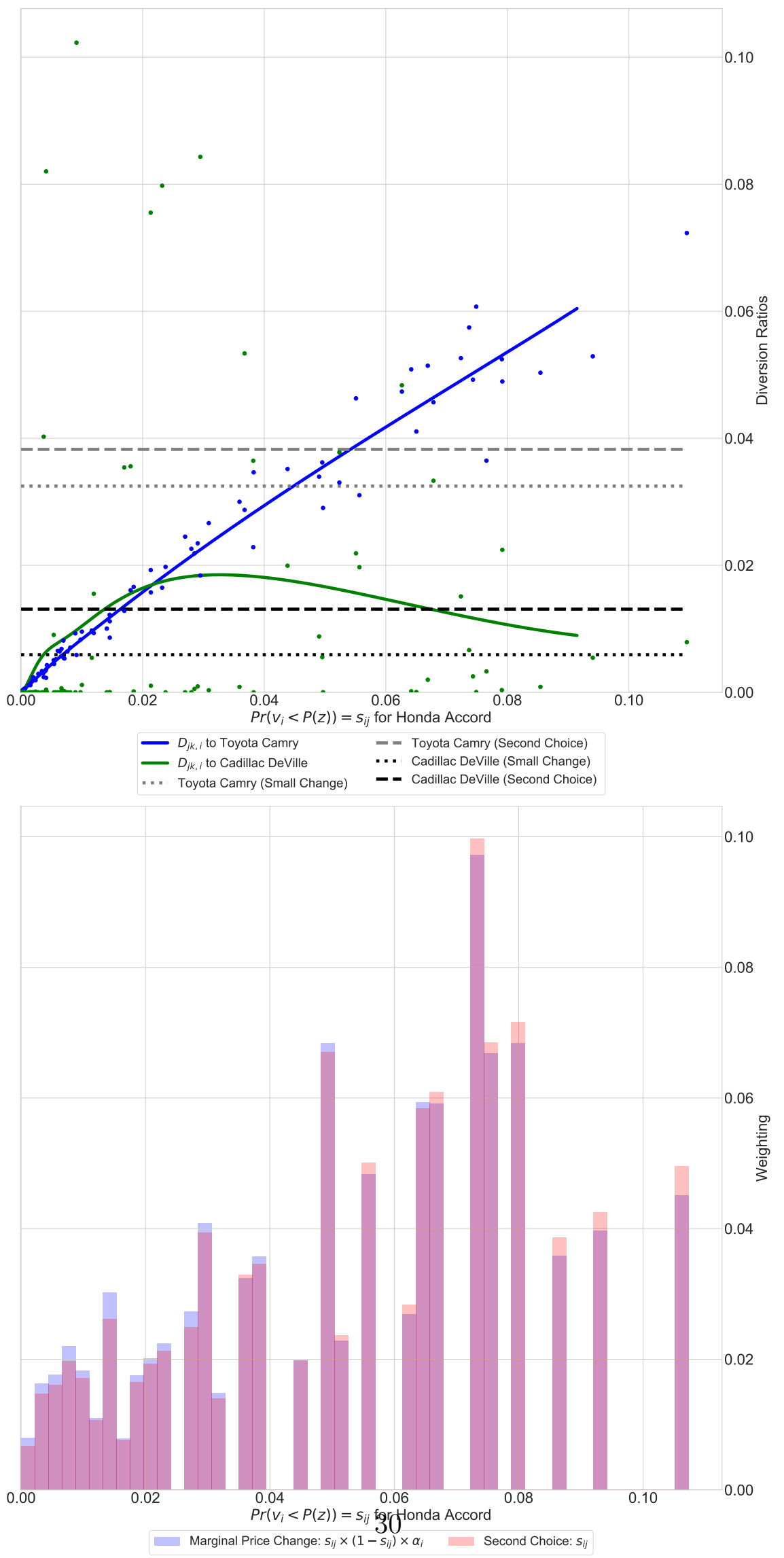

Figure 1: Decomposition of Diversion Measures for Honda Accord 


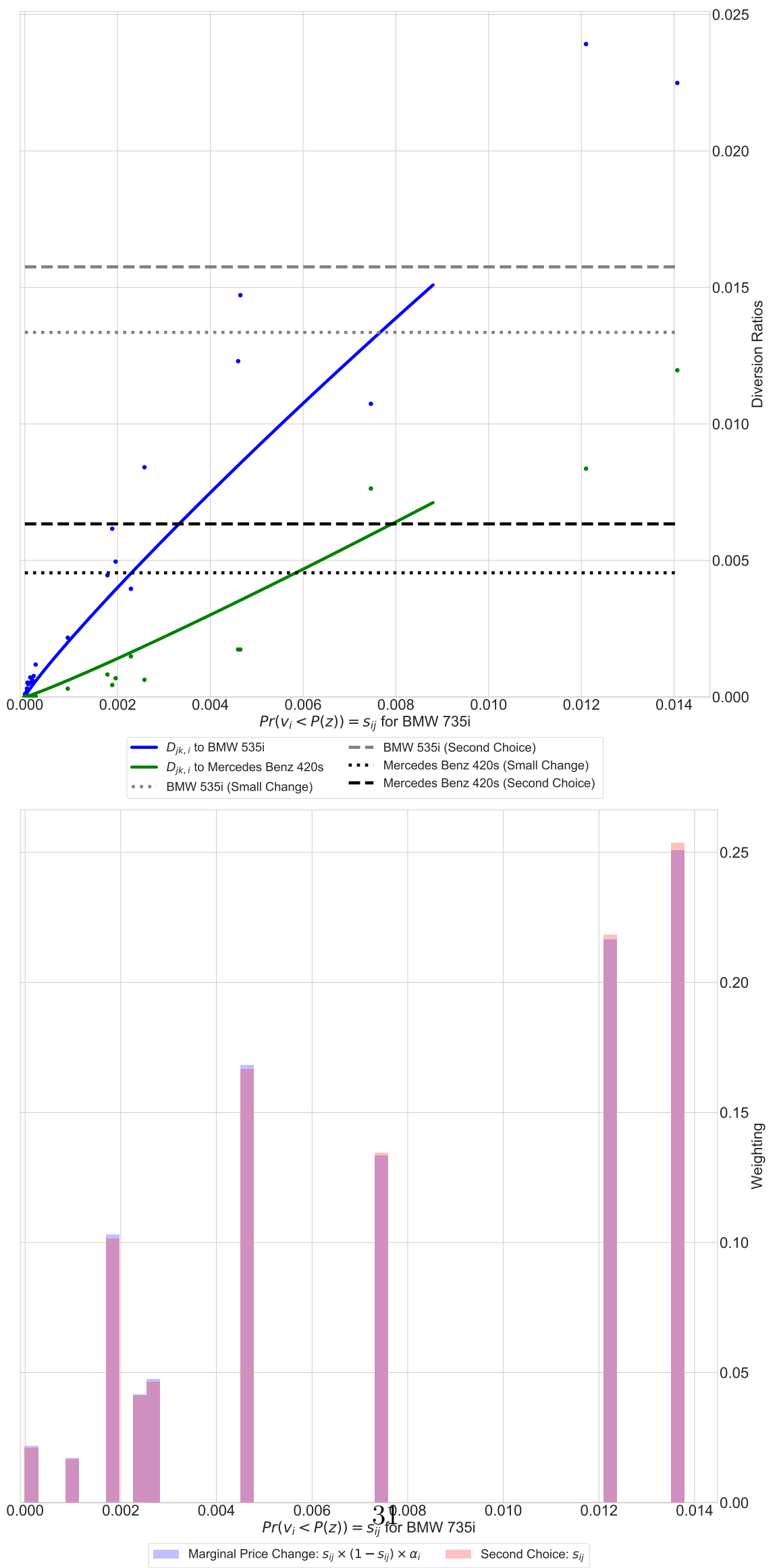

Figure 2: Decomposition of Diversion Measures for BMW 7 Series 
The four horizontal lines in the top panel of the figure indicate the average diversion from Accord to Camry (two lines in grey) and from Accord to Cadillac DeVille (two lines in black). The two measures for each pair of substitutes use the histograms in the lower panel to weight observations. The average diversion ratio from Accord to Camry obtained from a small price change is around $3.2 \%$; measuring the same diversion ratio from second-choice data gives an estimate of average diversion of around 3.8\%. The second-choice measure of average diversion is higher because the smoothed MTE for the Toyota Camry is upward sloping, and the histogram of weights for the second-choice measure places more weight on individuals to the right of the figure (with higher $s_{i j}$ 's).

Even though there are some individuals with very high diversion ratios from the Accord to the DeVille, the average diversion ratios from a small price change or second-choice data are both quite small, $<1 \%$, because the high diversion individuals receive such low weight (presumably because they represent a tiny fraction of likely Accord buyers). ${ }^{50}$

We observe a similar pattern in Figure 2, which considers diversion from the BMW 7-series to the BMW 5-series and the Mercedes 420s (three of the most expensive luxury vehicles in the dataset). Again, the majority of the points are around the origin, indicating that most simulated individuals don't purchase any of these high-end luxury vehicles. There is an increasing trend for diversion to both substitutes, as both the 5-series and the Mercedes are close substitutes to the 7 -series. However, even among these close substitutes, the largest individual diversion ratio is less than $2.5 \%$, and the average diversion measures are closer to $1.5 \%$ for the BMW 5-series (and 0.5\% for the Mercedes).

\subsection{Wald Estimates of Diversion Measures}

A different way to decompose heterogeneity in the diversion ratio measures is to start with the same question we began this article with: what would we measure by considering a ceteris paribus increase in price from $p_{j} \rightarrow p_{j}^{\prime}$ ? Different Wald estimators will produce

\footnotetext{
${ }^{50}$ We should caution that the figures can still obfuscate some of the underlying heterogeneity. Two individuals may have similar $s_{i j}$ "propensity scores" for the Accord, but for different reasons. The first may be on the margin of buying a car or not (low income, high price sensitivity). The second may be a buyer who is primarily shopping for luxury cars. Our figures may place these individuals at the same spot on the $\mathrm{x}$-axis making this kind of multi-dimensional heterogeneity hard to visualize. This also explains why the relationship between the Accord and DeVille can be downward sloping but still have second-choice diversion that is higher than diversion from a small price change.
} 
different (local) average diversion ratio measures. Consider the Wald estimate from (3):

$$
\operatorname{Wald}\left(z_{j}, z_{j}^{\prime}, x\right)=\frac{q_{k}\left(z_{j}^{\prime}, x\right)-q_{k}\left(z_{j}, x\right)}{\left|q_{j}\left(z_{j}^{\prime}, x\right)-q_{j}\left(z_{j}, x\right)\right|}
$$

For this example, we again focus solely on the BLP automobile data because there is less variation in the Nevo data in the underlying individual diversion measures $D_{j k, i}(x)$, and because the BLP data include product names that make the diversion ratios more interpretable.

We consider an increase in price $p_{j} \rightarrow p_{j}^{\prime}$ or reduction in quality $\xi_{j} \rightarrow \xi_{j}^{\prime}$ and plot the results for the Honda Accord and the BMW 7-series respectively in Figures 3 and 4, where the $\mathrm{x}$-axis corresponds to the share of initial Accord (BMW) consumers who continue to the purchase the Accord (BMW), and the y-axis corresponds to the Wald estimate of the diversion ratio. As we move toward the right, we consider larger price increases (or quality reductions) until the fraction of customers still purchasing the Accord or BMW approaches zero (the choke price). Dots on the graph denote $5 \%$ and $10 \%$ price increases, and a horizontal line marks the second-choice average (ATUT) diversion measure.

Figures 3 and 4 illustrate the fact that as we increase price (decrease quality) to the choke price (quality), the LATE estimates of diversion coincide with the second choice (ATUT) measure. The figures also show that the second-choice data and Wald estimates using quality $\left(\xi_{j}\right)$ are more similar to one another than they are to the Wald estimates from price. This is likely to hold more generally, and is consistent with our findings in Table 5 because the weights from Table 2 for a second-choice measure of diversion, $\left(\widetilde{w}_{i j}^{2 \text { nd choice }}(x) \propto \frac{s_{i j}(x)}{1-s_{i j}(x)}\right)$, and for a quality measure of diversion $\left(\widetilde{w}_{i j}^{\text {quality }}(x) \propto s_{i j}(x)\right)$ are very similar, whereas the price change intervention places more weight on more price-sensitive individuals $\left(\widetilde{w}_{i j}^{\text {price }}(x) \propto\right.$ $\left.\left|\alpha_{i}\right| s_{i j}(x)\right) .{ }^{51}$ In Figures 3 and 4, the average diversion ratio from a finite price change is smaller than the average diversion ratio obtained from quality changes or second-choice data. However, for other pairs of products, this pattern could be reversed. Indeed, the relationship between the LATE for a given finite price change, and a second-choice measure need not even be monotone (e.g., the measured (local) average diversion ratio may be increasing for small price changes, but decreasing for larger ones). More generally, the relationship between the average diversion for a finite price change vs. second-choice data is driven by the covariance between $\alpha_{i}$ and the corresponding shares (weights) $s_{i j}(x)$, as illustrated in the previous

${ }^{51}$ This is particularly true if $\frac{s_{i j}(x)}{1-s_{i j}(x)} \approx s_{i j}(x)$ when shares are small. Here "price" is effectively any characteristic with a random coefficient and "quality" is the utility index or any "vertical" characteristic lacking a random coefficient. The correct LATE weights are proportional to $q\left(z_{j}, x\right)-q\left(z_{j}^{\prime}, x\right)$ rather than the derivative of $q_{j}\left(Z_{j}, x\right)$ at $z_{j}$. 
section. Without placing strong restrictions on the underlying heterogeneity, it is impossible to make statements like: "Small price changes lead to lower estimates of diversion ratios than second-choice data." 52

\subsection{Willingness to Pay Measures}

\begin{tabular}{|c|c|c|c|c|c|c|c|c|c|c|}
\hline & \multicolumn{4}{|c|}{ Individual } & \multirow[b]{2}{*}{ Nevo } & \multirow[b]{2}{*}{ Nevo } & \multicolumn{4}{|c|}{ Aggregate } \\
\hline & BLP & BLP & BLP & BLP & & & BLP & BLP & Nevo & Nevo \\
\hline $\log \left(s_{j t}\right)$ & $\begin{array}{l}1.0749^{*} \\
(0.0001)\end{array}$ & $\begin{array}{l}1.0519^{*} \\
(0.0001)\end{array}$ & $\begin{array}{l}0.9955^{*} \\
(0.0000)\end{array}$ & $\begin{array}{c}0.9955^{*} \\
(0.0000)\end{array}$ & $\begin{array}{l}1.0255^{*} \\
(0.0002)\end{array}$ & $\begin{array}{l}1.0353^{*} \\
(0.0002)\end{array}$ & $\begin{array}{l}0.7669^{*} \\
(0.0087)\end{array}$ & $\begin{array}{l}0.9265^{*} \\
(0.0061)\end{array}$ & $\begin{array}{l}1.0144^{*} \\
(0.0020)\end{array}$ & $\begin{array}{c}1.0105^{*} \\
(0.0010)\end{array}$ \\
\hline $\log \left(D_{j, 0}\right)$ & & $-0.2233^{*}$ & $-0.0032^{*}$ & & & $0.1090^{*}$ & & $-0.6733^{*}$ & & $0.1786^{*}$ \\
\hline & & $(0.0005)$ & $(0.0002)$ & & & (0.0009) & & (0.0114) & & $(0.0022)$ \\
\hline $\log \left(\left\|\alpha_{i}\right\|\right)$ & & & $\begin{array}{c}-1.0113^{*} \\
(0.0005)\end{array}$ & $\begin{array}{c}-1.0164^{*} \\
(0.0004)\end{array}$ & & & & & & \\
\hline$R^{2}$ & 0.9951 & 0.9967 & 0.9997 & 0.9997 & 0.9975 & 0.9981 & 0.7784 & 0.9139 & 0.9915 & 0.9978 \\
\hline Adjusted $R^{2}$ & 0.9951 & 0.9967 & 0.9997 & 0.9997 & 0.9975 & 0.9981 & 0.7783 & 0.9138 & 0.9915 & 0.9978 \\
\hline Observations & 436199 & 436199 & 436199 & 436199 & 45051 & 45051 & 2217 & 2217 & 2256 & 2256 \\
\hline
\end{tabular}

Table 7: Correlation with WTP Measure for Nevo (2000b) and Berry et al. (1999).

For individual-draw specifications $s_{i j t}(x)$ and $D_{j 0, i}(x)$ are used.

Approximately half of observations for $\operatorname{BLP} W T P(i, j)$ are excluded because $W T P(i, j) \approx 0$ to machine precision.

In Section 3.8, we demonstrate the relationship between the willingness-to-pay (WTP) measure (often used to analyze bargained outcomes and hospital mergers), the individual share $s_{i j}(x)$, the diversion to the outside good $D_{j 0, i}(x)$, and the individual price sensitivity $\alpha_{i}$. More specifically, in (15) we showed that $W T P_{j}=W T P_{i j} \partial F_{i}=\int D_{j 0, i}(x) \frac{s_{i j}(x)}{\left|\alpha_{i}\right| \cdot s_{i 0}(x)} \partial F_{i}=$ $\int \frac{s_{i j}(x)}{\left|\alpha_{i}\right|\left(1-s_{i j}(x)\right)} \partial F_{i}$. We can illustrate this relationship by considering the following two (decomposition) regressions:

$$
\begin{aligned}
\ln W T P_{i j t}=\beta_{0}+\beta_{1} \ln s_{j t, i}(x)+\beta_{2} \ln D_{j t 0, i}(x)+\beta_{3} \ln \left|\alpha_{i t}\right| & +\varepsilon_{i j t} \\
\ln W T P_{j t}=\gamma_{0}+\gamma_{1} \ln s_{j t}(x)+\gamma_{2} \ln D_{j t 0}(x) & +\varepsilon_{j t}
\end{aligned}
$$

To run these regressions, we construct the WTP measure for every individual, in every market, for each product. For example, $W T P_{i j t}$ might represent the willingness to pay of a particular consumer for having a Honda Accord in his or her choice set in 1990; or it might represent the willingness to pay to have Apple Cinnamon Cheerios on the shelf of a supermarket in a particular week. $W T P_{j t}$ represents the average of the individual measures over all of the households $i$.

\footnotetext{
${ }^{52}$ In some sense, this should be obvious because diversion ratios must sum to one, and for one diversion ratio to go up, others (including the outside good) must go down.
} 

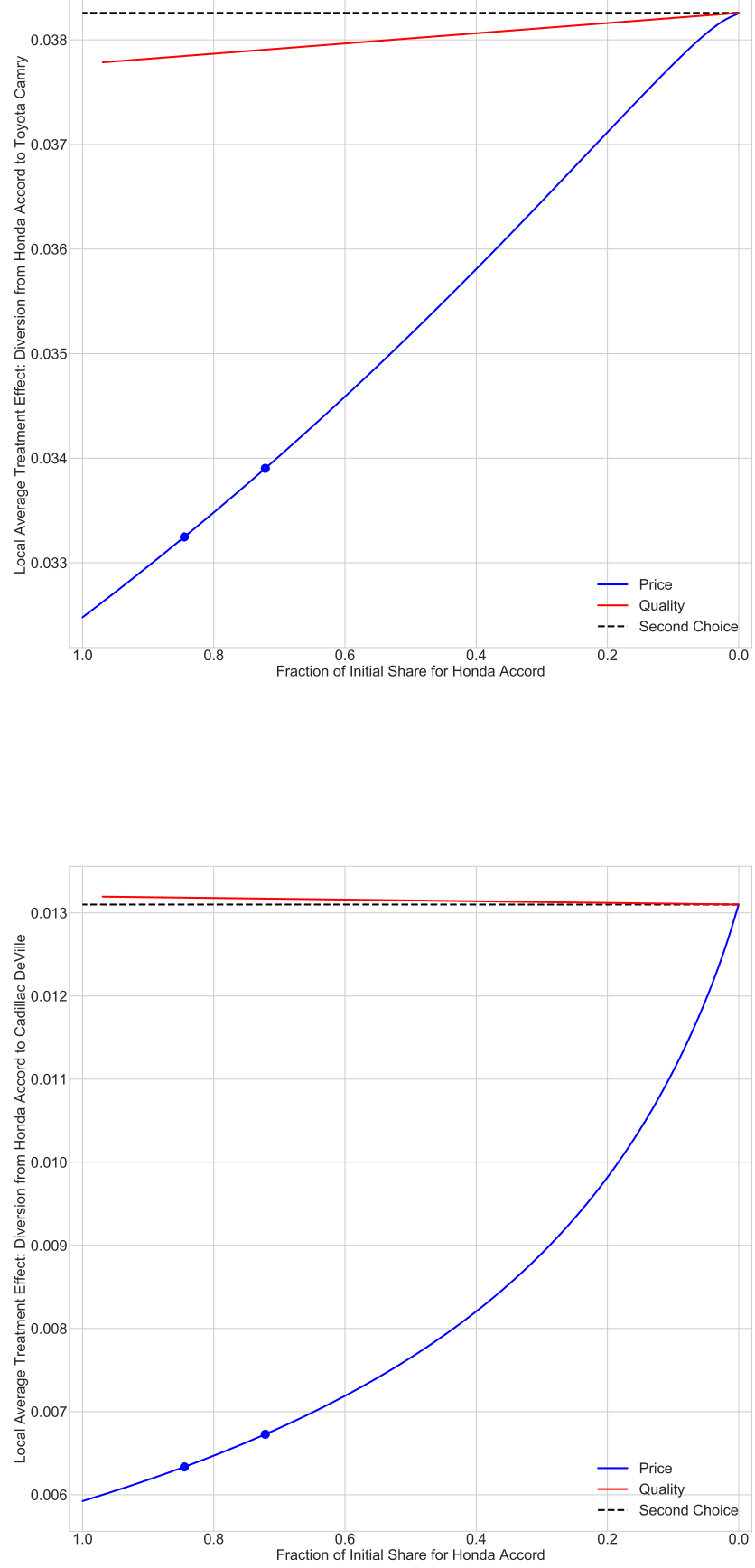

Figure 3: Local Average Diversion Measures from Accord to Camry and Deville 

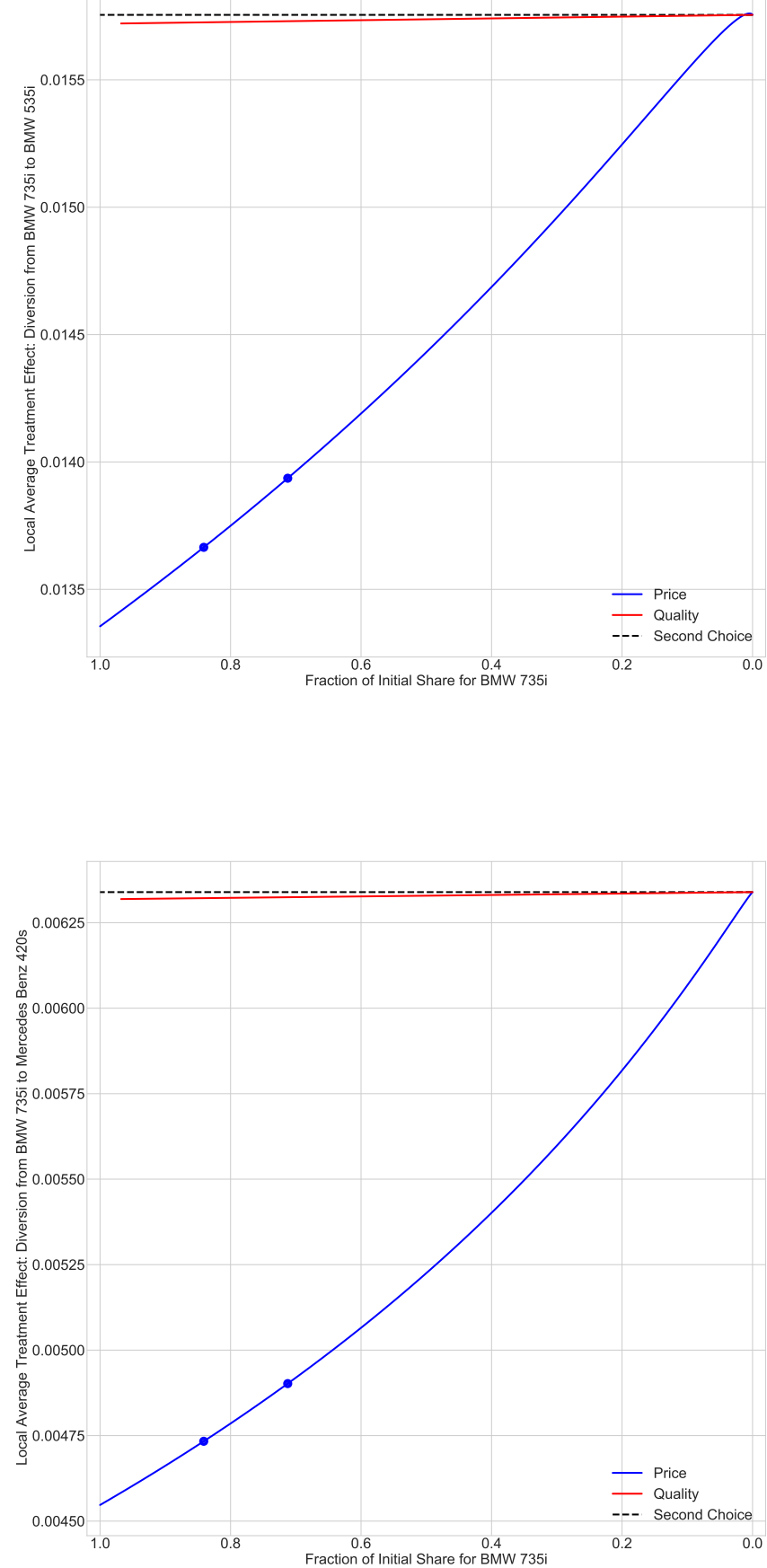

Figure 4: Local Average Diversion Measures from BMW 7-series to 5-Series and Mercedes 
We report the regression estimates in Table 7 . At the individual level, we are able to explain over $99 \%$ of the variance in the individual level $W T P_{i j}$ measure using just $s_{j t, i}(x)$ and $D_{j t 0, i}(x)$ for both the BLP and Nevo examples. In accordance with (15), the third and fourth columns demonstrate in the BLP application that once we control for the price sensitivity $\ln \left(\left|\alpha_{i}\right|\right)$, diversion to the outside good at the individual level is no longer economically meaningful.

What is perhaps more surprising is that we are also able to explain average market-level willingness to pay. The average willingness to pay for access to a Camry or Cheerios in the choice set can be explained using only the market level share $s_{j t}(x)$ and outside good diversion $D_{j 0}(x)$. In the Nevo (fake) data, we are able to explain $99.1 \%$ of the variance in $W T P_{j}$ using just $s_{j t}(x)$ and $99.8 \%$ of variance once we also include the (market-level) diversion to the outside good. We see similar results for the BLP data where we explain roughly $78 \%$ of the variance using just $s_{j t}(x)$ and $91.3 \%$ of the variance in $W T P_{j}$ using $s_{j t}(x)$ and market-level diversion to the outside good $D_{j 0 t}(x)$. We should caution that at the aggregate level, this is neither a sufficient statistic representation nor a decomposition in the sense that while the coefficient on $\ln s_{j t}(x)$ is approximately one, the coefficient on $D_{j 0 t}(x)$ is not easily discerned without running the regression. In fact, it has a different sign in the Nevo data and the BLP data (because of how it covaries at the individual level with the price sensitivity $\left.\left|\alpha_{i}\right|\right){ }^{53}$

What this does highlight is that estimates of $W T P$ are largely about own share $s_{j t}(x)$, which is often observed as data at the market level (and possibly at the individual level for some datasets - such as patient discharge data for hospitals). It also highlights the value of accurately measuring diversion to the outside good, including possibly from additional (micro) moments. Second-choice data, such as knowing what fraction of consumers would switch to a hospital outside the geographic market if a particular hospital were to close, may also be valuable such as in Raval et al. (2019). ${ }^{54}$

\section{Conclusion}

We provide a treatment effects interpretation of diversion ratios, and demonstrate how different ceteris paribus interventions (price changes, quality changes, characteristic changes,

\footnotetext{
${ }^{53}$ Individual outside good diversion is positively correlated with $\alpha_{i}$ in the BLP data and negatively correlated with $\alpha_{i}$ in the Nevo data. This may seem surprising at first, but the demographics (kids and income) and the relationship between price and the constant in the Nevo data induce the negative correlation.

${ }^{54}$ Recall that second-choice data integrates $s_{i k}(x)$ over the weights $\frac{s_{i j}(x)}{1-s_{i j}(x)}$, while WTP integrates $\frac{1}{\left|\alpha_{i}\right|}$ over the same set of weights, as demonstrated in Section 3.8.
} 
and assortment changes) can be used to identify diversion ratios. While these measures of diversion ratios will not in general agree with one another, we provide a framework to decompose these average measures into individual diversion ratios (policy invariant structural parameters) and a set of weights, which vary with the intervention. We provide additional results showing how willingness-to-pay (WTP) is related to diversion to the outside good, and individual choice probabilities.

The object of interest may vary with the application. Sometimes the object of interest is a price change from a merger simulation or UPP calculation for a horizontal merger, in which case the researcher is likely interested in diversion ratios measured from small price changes. In other cases the relevant object may be the substitution induced from quality increases/reductions or from changes in product assortment. In an ideal world, the object of interest would coincide with the data available to the researcher. In practice, researchers may have access to additional data from customer surveys, win-loss data, or customer switching behavior, which may or may not coincide with the diversion measure of interest. When these measures do not perfectly coincide, our framework provides a way to interpret discrepancies between different diversion measures.

In many cases researchers may still want to estimate a fully parametric model of demand (or supply and demand) such as in Berry et al. (1995) or Nevo (2000a). We hope that a better understanding of diversion ratios can help make the outputs of these models more interpretable. In simulations, we find that the diversion ratios measured from parametric models in two applications are perhaps more similar than one might have anticipated. For the automobile example, second-choice measures of diversion ratios are within $20 \%$ of measures based on small price changes, so that a $5 \%$ diversion ratio might be measured in the range of $(4 \%, 6 \%)$. For the simulated cereal data example, the estimated measures are even less dispersed, so that they are generally within $5 \%$ of one another. We caution that these findings are not guaranteed (or even likely) to hold in all potential examples, and that both settings have relatively large outside good shares. This is important, because our simulations also indicate that measures of diversion ratios that rely on parametric models tend to be sensitive to the specification of the outside good share or market size, indicating a potential need for additional data or moment restrictions (such as in Berry et al. (2004)) for this class of models. 


\section{References}

Angrist, J. D., K. Graddy, and G. W. Imbens (2000): "The interpretation of instrumental variables estimators in simultaneous equations models with an application to the demand for fish," The Review of Economic Studies, 67, 499-527.

BERRY, S. (1994): "Estimating discrete-choice models of product differentiation," RAND Journal of Economics, 25, 242-261.

Berry, S., J. Levinsohn, And A. Pakes (1995): "Automobile Prices in Market Equilibrium," Econometrica, 63, 841-890.

- (1999): "Voluntary Export Restraints on Automobiles: Evaluating a Trade Policy," American Economic Review, 89, 400-430.

- (2004): "Differentiated Products Demand Systems from a Combination of Micro and Macro Data: The New Car Market," Journal of Political Economy, 112, 68-105.

Berry, S. T. AND P. A. Haile (2014): "Identification in Differentiated Products Markets Using Market Level Data," Econometrica, 82, 1749-1797.

Capps, C., D. Dranove, And M. Satterthwaite (2003): "Competition and Market Power in Option Demand Markets," The RAND Journal of Economics, 34, 737-763.

Carlton, D. W. (2010): "Revising the Horizontal Merger Guidelines," Journal of Competition Law and Economics, 6, 619-652.

Carlton, D. W. And M. Israel (2010): "Will the New Guidelines Clarify or Obscure Antitrust Policy?" The Antitrust Source, 1-4.

Carneiro, P., J. J. Heckman, and E. J. Vytlacil (2011): "Estimating Marginal Returns to Education," American Economic Review, 101, 2754-81.

Chetty, R. (2009): "Sufficient Statistics for Welfare Analysis: A Bridge Between Structural and Reduced-Form Methods," Annual Review of Economics, 1, 451-488.

Cheung, L. (2011): "The Upward Pricing Pressure Test for Merger Analysis: An Empirical Examination," Working Paper.

Competition and Markets Authority (2017): "Retail Mergers Commentary," April 10, https://www.gov.uk/government/publications/retail-mergers-commentary-cma62. 
Conlon, C. and J. Gortmaker (2020): "Best Practices for Demand Estimation with pyBLP," RAND Journal of Economics.

Conlon, C. And J. H. Mortimer (2013): "Demand Estimation Under Incomplete Product Availability," American Economic Journal: Microeconomics, 5, 1-30.

Conlon, C. And N. RaO (2019): "The Price of Liquor is Too Damn High," Working Paper.

Crawford, G. S. And A. Yurukoglu (2012): "The Welfare Effects of Bundling in Multichannel Television Markets," American Economic Review, 102, 643-85.

Ericson, K. M. AND A. Starc (2015): "Measuring Consumer Valuation of Limited Provider Networks," American Economic Review, 105, 115-19.

Farrell, J. And C. Shapiro (2010): "Antitrust Evaluation of Horizontal Mergers: An Economic Alternative to Market Definition," The B.E. Journal of Theoretical Economics, $10,1-41$.

Gotts, I. K. (2010): "Are the New Guidelines Representational Art Or Pop Art in the End?" The Antitrust Source, 1-4.

Gowrisankaran, G., A. Nevo, and R. Town (2015): "Mergers When Prices Are Negotiated: Evidence from the Hospital Industry," American Economic Review, 105, 172203.

Hausman, J. A. (2010): "2010 Merger Guidelines: Empirical Analysis," Working Paper.

Heckman, J. J. (2010): "Building Bridges Between Structural and Program Evaluation Approaches to Evaluating Policy," Journal of Economic Literature, 48, 356-398.

Heckman, J. J. and E. Vytlacil (2005): "Structural Equations, Treatment Effects, and Econometric Policy Evaluation," Econometrica, 73, 669-738.

Ho, K. (2006): "The welfare effects of restricted hospital choice in the US medical care market," Journal of Applied Econometrics, 21, 1039-1079.

- (2009): "Insurer-Provider Networks in the Medical Care Market," American Economic Review, 99, 393-430. 
Ho, K. And R. S. LeE (2019): "Equilibrium Provider Networks: Bargaining and Exclusion in Health Care Markets," American Economic Review, 109, 473-522.

Imbens, G. W. And J. D. Angrist (1994): "Identification and Estimation of Local Average Treatment Effects," Econometrica, 62, 467-475.

JAFFE, S. AND E. WEYL (2013): "The first-order approach to merger analysis," American Economic Journal: Microeconomics, 5, 188-218.

Jaffe, S. And G. Weyl (2010): "Linear Demand Systems are Inconsistent with Discrete Choice," The B.E. Journal of Theoretical Economics, 10, 52-52.

Katz, M. L. And C. Shapiro (2003): "Critical Loss: Let's Tell the Whole Story," Antitrust Magazine.

Manski, C. And D. McFadden (1981): Structural Analysis of Discrete Data with Econometric Applications, The MIT Press.

Mansley, R., N. Miller, C. Ryan, and M. Weinberg (2019): "Notes on the Nested Logit Demand Model," http://www.nathanhmiller.org/nlnotes.pdf, notes.

McFadden, D. And K. Train (2000): "Mixed MNL Models for Discrete Response," Journal of Applied Econometrics, 15, 447-470.

Miller, N., M. Remer, C. Ryan, And G. Sheu (2016): "Pass-Through and the Prediction of Merger Price Effects," Journal of Industrial Economics, 64, 684-709.

Miravete, E. J., K. Seim, And J. Thurk (2018): "Market Power and the Laffer Curve," Econometrica, 86, 1651-1687.

Nevo, A. (2000a): "Mergers with differentiated products: the case of the ready-to-eat cereal industry," RAND Journal of Economics, 31, 395-421.

(2000b): “A Practitioner's Guide to Estimation of Random Coefficients Logit Models of Demand (including Appendix)," Journal of Economics and Management Strategy, 9, $513-548$.

(2001): "Measuring Market Power in the Ready-to-Eat Cereal Industry," Econometrica, 69, 307-342. 
Raval, D., T. Rosenbaum, and N. Wilson (2019): "Using Disaster Induced Closures to Evaluate Discrete Choice Models of Hospital Demand," Working Paper.

Reynolds, G. And C. Walters (2008): "The use of customer surveys for market definition and the competitive assessment of horizontal mergers," Journal of Competition Law and Economics, 4, 411-431.

Schmalensee, R. (2009): "Should New Merger Guidelines Give UPP Market Definition?" Antitrust Chronicle, 12, 1.

Town, R. And G. Vistnes (2001): "Hospital competition in HMO networks," Journal of Health Economics, 20, 733-753.

WALD, A. (1940): "The Fitting of Straight Lines if Both Variables are Subject to Error," Ann. Math. Statist., 11, 284-300.

Willig, R. (2011): "Unilateral Competitive Effects of Mergers: Upward Pricing Pressure, Product Quality, and Other Extensions," Review of Industrial Organization, 39, 19-38.

Working, E. J. (1927): "What Do Statistical "Demand Curves" Show?" The Quarterly Journal of Economics, 41, 212-235. 


\section{Appendices}

\section{A. Theory Appendix}

\section{A.1. Proofs and Derivations}

\section{Analogue to LATE Theorem (Imbens and Angrist, 1994)]}

Under the following conditions:

(a) Mutually Exclusive and Exhaustive Discrete Choice: $d_{i j} \in\{0,1\}$ and $\sum_{j \in \mathcal{J}} d_{i j}=1$.

(b) Exclusion: $u_{i k}\left(p_{j}\right)=u_{i k}\left(p_{j}^{\prime}\right)$ for all $k \neq j$ and any $\left(p_{j}, p_{j}^{\prime}\right)$;

(c) Monotonicity: $u_{i j}\left(p_{j}^{\prime}\right) \leq u_{i j}\left(p_{j}\right)$ for all $i$ and any $\left(p_{j}^{\prime}>p_{j}\right)$; and

(d) Existence of a first-stage: $\operatorname{Pr}\left(d_{i j}\left(p_{j}\right)=0\right) \neq \operatorname{Pr}\left(d_{i j}\left(p_{j}^{\prime}\right)=0\right)$ for $\left(p_{j}^{\prime}>p_{j}\right)$;

(e) Random Assignment: $\left(u_{i j}\left(P_{j}\right), u_{i k}\left(P_{j}\right)\right) \perp P_{j}$,

then the Wald estimator from (3):

$$
\frac{q_{k}\left(p_{j}^{\prime}, x\right)-q_{k}\left(p_{j}, x\right)}{-\left(q_{j}\left(p_{j}^{\prime}, x\right)-q_{j}\left(p_{j}, x\right)\right)}=E\left[D_{j k, i}(x) \mid d_{i j}\left(p_{j}, x\right)>d_{i j}\left(p_{j}^{\prime}, x\right)\right] .
$$

\section{Proof of Proposition 1:}

We suppress $x$ because everything is done conditional on $x$. We begin by observing under the discrete choice assumption $q_{k}=M \cdot s_{k}$ where $s_{k}$ is the market share of good $k$ (including an outside option) and $M$ is the size of the market:

$$
\frac{q_{k}\left(p_{j}^{\prime}, x\right)-q_{k}\left(p_{j}, x\right)}{-\left(q_{j}\left(p_{j}^{\prime}, x\right)-q_{j}\left(p_{j}, x\right)\right)}=\frac{s_{k}\left(p_{j}^{\prime}, x\right)-s_{k}\left(p_{j}, x\right)}{-\left(s_{j}\left(p_{j}^{\prime}, x\right)-s_{j}\left(p_{j}, x\right)\right)}
$$

We also use the definition that $s_{k}\left(P_{j}, x\right)=E\left[d_{i k}\left(P_{j}\right)=1 \mid x\right]=E\left[d_{i k}\left(P_{j}\right) \mid x\right]$. This says the market share is equal to the average purchase probability when choices are discrete, exhaustive, and mutually exclusive and follows from (a).

Define $\bar{u}_{i}=\max _{k^{\prime}} u_{i k^{\prime}}$ for $k^{\prime} \in \mathcal{J} \backslash\{j, k\}$ (the best product for $i$ other than $(j, k)$ ). Notice 
that $\bar{u}_{i}\left(p_{j}\right)=\bar{u}_{i}\left(p_{j}^{\prime}\right)$ for any $\left(p_{j}, p_{j}^{\prime}\right)$ (the Exclusion restriction). Consider the numerator:

$$
\begin{aligned}
E\left[d_{i k}\left(P_{j}\right) \mid P_{j}=p_{j}^{\prime}\right] & =\operatorname{Pr}\left(u_{i k}\left(p_{j}^{\prime}\right)>u_{i j}\left(p_{j}^{\prime}\right) ; u_{i k}\left(p_{j}^{\prime}\right)>\bar{u}_{i}\left(p_{j}^{\prime}\right) \mid P_{j}=p_{j}^{\prime}\right) \\
& =\operatorname{Pr}\left(u_{i k}>u_{i j}\left(p_{j}^{\prime}\right) ; u_{i k}>\bar{u}_{i} \mid P_{j}=p_{j}^{\prime}\right) \quad \text { by exclusion } \\
& =\operatorname{Pr}\left(u_{i k}>u_{i j}\left(p_{j}^{\prime}\right) ; u_{i k}>\bar{u}_{i}\right) \quad \text { by random assignment } \\
E\left[d_{i k}\left(P_{j}\right) \mid P_{j}=p_{j}\right] & =\operatorname{Pr}\left(u_{i k}\left(p_{j}\right)>u_{i j}\left(p_{j}\right) ; u_{i k}\left(p_{j}\right)>\bar{u}_{i}\left(p_{j}\right) \mid P_{j}=p_{j}\right) \\
& =\operatorname{Pr}\left(u_{i k}>u_{i j}\left(p_{j}\right) ; u_{i k}>\bar{u}_{i} \mid P_{j}=p_{j}\right) \quad \text { by exclusion } \\
& =\operatorname{Pr}\left(u_{i k}>u_{i j}\left(p_{j}\right) ; u_{i k}>\bar{u}_{i}\right) \quad \text { by random assignment }
\end{aligned}
$$

This means we can re-write the numerator:

$$
\begin{aligned}
E\left[d_{i k}\left(P_{j}\right) \mid P_{j}=p_{j}^{\prime}\right]-E\left[d_{i k}\left(P_{j}\right) \mid P_{j}=p_{j}\right] & =\operatorname{Pr}\left(u_{i k}>u_{i j}\left(p_{j}^{\prime}\right) ; u_{i k}>\bar{u}_{i}\right)-\operatorname{Pr}\left(u_{i k}>u_{i j}\left(p_{j}\right) ; u_{i k}>\bar{u}_{i}\right) \\
& =\operatorname{Pr}\left(u_{i j}\left(p_{j}^{\prime}\right)<u_{i k}<u_{i j}\left(p_{j}\right) ; u_{i k}>\bar{u}_{i}\right) \quad \text { by Monotoncity } \\
& =\operatorname{Pr}\left(u_{i k}>u_{i j}\left(p_{j}^{\prime}\right) ; u_{i j}\left(p_{j}\right)>u_{i k} ; u_{i k}>\bar{u}_{i}\right) \\
& =\operatorname{Pr}\left(\max \left\{u_{i k}, \bar{u}_{i}\right\}>u_{i j}\left(p_{j}^{\prime}\right) ; u_{i j}\left(p_{j}\right)>\max \left\{u_{i k}, \bar{u}_{i}\right\} ; u_{i k}>\bar{u}_{i}\right) \\
& =\operatorname{Pr}\left(u_{i k}>\bar{u}_{i} ; d_{i j}\left(p_{j}^{\prime}\right)=0 ; d_{i j}\left(p_{j}\right)=1\right) \quad \text { by defn } d_{i j}
\end{aligned}
$$

The denominator, beginning with the exclusion restriction:

$$
\begin{aligned}
E\left[d_{i j}\left(P_{j}\right) \mid P_{j}=p_{j}^{\prime}\right] & =1-\operatorname{Pr}\left(u_{i j}\left(p_{j}^{\prime}\right)>u_{i k}\left(p_{j}^{\prime}\right) ; u_{i j}\left(p_{j}^{\prime}\right)>\bar{u}_{i}\left(p_{j}^{\prime}\right) \mid P_{j}=p_{j}^{\prime}\right) \\
& =1-\operatorname{Pr}\left(u_{i j}\left(p_{j}^{\prime}\right)>\max \left\{u_{i k}, \bar{u}_{i}\right\}\right) \quad \text { by random assignment } \\
E\left[d_{i j}\left(P_{j}\right) \mid P_{j}=p_{j}\right] & =1-\operatorname{Pr}\left(u_{i k}\left(p_{j}\right)>u_{i j}\left(p_{j}\right) ; u_{i k}\left(p_{j}\right)>\bar{u}_{i}\left(p_{j}\right) \mid P_{j}=p_{j}\right) \\
& =1-\operatorname{Pr}\left(u_{i j}\left(p_{j}\right)>\max \left\{u_{i k}, \bar{u}_{i}\right\}\right) \quad \text { by random assignment }
\end{aligned}
$$

And we can re-write the denominator:

$$
\begin{aligned}
E\left[d_{i j}\left(P_{j}\right) \mid P_{j}=p_{j}^{\prime}\right]-E\left[d_{i j}\left(P_{j}\right) \mid P_{j}=p_{j}\right] & =\operatorname{Pr}\left(u_{i j}\left(p_{j}\right)>\max \left\{u_{i k}, \bar{u}_{i}\right\}\right)-\operatorname{Pr}\left(u_{i j}\left(p_{j}^{\prime}\right)>\max \left\{u_{i k}, \bar{u}_{i}\right\}\right) \\
& =\operatorname{Pr}\left(u_{i j}\left(p_{j}^{\prime}\right)<\max \left\{u_{i k}, \bar{u}_{i}\right\}<u_{i j}\left(p_{j}\right)\right) \quad \text { by Monotoncity } \\
& =\operatorname{Pr}\left(\max \left\{u_{i k}, \bar{u}_{i}\right\}>u_{i j}\left(p_{j}^{\prime}\right) ; u_{i j}\left(p_{j}\right)>\max \left\{u_{i k}, \bar{u}_{i}\right\}\right) \\
& =\operatorname{Pr}\left(d_{i j}\left(p_{j}^{\prime}\right)=0 ; d_{i j}\left(p_{j}\right)=1\right) \quad \text { by defn } d_{i j}
\end{aligned}
$$


The ratio in (A.1) is: ${ }^{55}$

$$
\begin{aligned}
\frac{E\left[d_{i k}\left(p_{j}^{\prime}, x\right)\right]-E\left[d_{i k}\left(p_{j}, x\right)\right]}{E\left[d_{i j}\left(p_{j}^{\prime}, x\right)\right]-E\left[d_{i j}\left(p_{j}, x\right)\right]} & =\frac{\operatorname{Pr}\left(u_{i k}>\bar{u}_{i} ; d_{i j}\left(p_{j}^{\prime}\right)=0 ; d_{i j}\left(p_{j}\right)=1\right)}{\operatorname{Pr}\left(d_{i j}\left(p_{j}^{\prime}\right)=0 ; d_{i j}\left(p_{j}\right)=1\right)} \\
& =\operatorname{Pr}\left(u_{i k}>\bar{u}_{i} \mid d_{i j}\left(p_{j}^{\prime}\right)=0 ; d_{i j}\left(p_{j}\right)=1\right) \quad \text { by Bayes' Rule } \\
& =E\left[\mathbf{1}\left[u_{i k}>\bar{u}_{i}\right] \mid d_{i j}\left(p_{j}^{\prime}\right)<d_{i j}\left(p_{j}\right)\right] \\
& =E\left[D_{j k, i}(x) \mid d_{i j}\left(p_{j}^{\prime}, x\right)<d_{i j}\left(p_{j}, x\right)\right] \square .
\end{aligned}
$$

The last line is merely the definition of the individual diversion ratio: that individual $i$ prefers $k$ to any non $j$ alternative so that $i$ 's "treatment effect" is given by: $Y_{i}(1)-Y_{i}(0)=\mathbf{1}\left[u_{i k}>\bar{u}_{i}\right]$. Notice this satisfies the "Independence" assumption of Imbens and Angrist (1994). That is, $D_{j k, i}(x)=\mathbf{1}\left[u_{i k}(x)>\bar{u}_{i}(x)\right]$ does not depend on the "instrument" $P_{j}$.

In words, the Wald estimator delivers the expected treatment effect on the compliers (ie: individuals for whom $\left(d_{i j}\left(p_{j}\right)=1, d_{i j}\left(p_{j}^{\prime}\right)=0\right)$. The compliers are the individuals who would have purchased $j$ at price $p_{j}$ and who do not purchase $j$ at price $p_{j}^{\prime}$.

\section{A.2. Link to marginal treatment effect: Derivation of (6)}

Because we have a latent index model for the discrete choice problem this is straightforward. The conventional definition of the marginal treatment effect is literally the treatment effect for the individual indifferent between treatment and non-treatment:

$$
\begin{aligned}
\operatorname{MTE}\left(v_{s}\right) & =E\left[Y_{i}(1)-Y_{i}(0) \mid \operatorname{Pr}\left(T_{i}=1\right)=\nu_{i}\right] \\
& =E\left[\mathbf{1}\left[u_{i k}\left(\nu_{i}\right)>\bar{u}_{i}\left(\nu_{i}\right)\right] \mid u_{i j}\left(\nu_{i}\right)=\max \left\{u_{i k}\left(\nu_{i}\right), \bar{u}_{i}\left(\nu_{i}\right)\right\}\right] \\
& =E\left[D_{j k, i}\left(x, \nu_{i}\right) \mid u_{i j}\left(\nu_{i}\right)=\max \left\{u_{i k}\left(\nu_{i}\right), \bar{u}_{i}\left(\nu_{i}\right)\right\}\right]
\end{aligned}
$$

One possible interpretation of what $\nu_{i}$ means is that $\nu_{i}=\varepsilon_{i j}$ in a random utility model so that $u_{i j}=\overline{u_{i j}}+\varepsilon_{i j}$. That is we could hold all other $\varepsilon_{i,-j}$ fixed (part of $x$ ) and integrate out over just the distribution of unobserved tastes for $j$. In fact, this would be the convention from Heckman and Vytlacil (2005). Their idea is to rank all individuals by their propensity score, the probability of not purchasing $j: H\left(\nu_{i}\right)=\operatorname{Pr}\left[d_{i j}\left(\nu_{i}, x\right)=1\right]$ and to plot the $\operatorname{MTE}\left(\nu_{i}\right)$ against the propensity score $H\left(\nu_{i}\right)$. This becomes awkward with multiple choices because we consider the marginal distribution with respect to $\varepsilon_{i, j}$ where $\varepsilon_{i,-j}$ is integrated out.

For the random coefficients logit, it is easier to work with the "individuals" after inte-

\footnotetext{
${ }^{55}$ This requires the "first stage" assumption to avoid division by zero: $\operatorname{Pr}\left(d_{i j}\left(p_{j}^{\prime}\right)=0 ; d_{i j}\left(p_{j}\right)=1\right) \neq 0$.
} 
grating out $\varepsilon_{i}$ since that admits a closed form. In this case:

$$
D_{j k, i}(x)=\frac{\frac{\partial s_{i k}}{\partial p_{j}}(x)}{-\frac{\partial s_{i j}}{\partial p_{j}}(x)}=\frac{-\alpha_{i} s_{i k}(x) s_{i j}(x)}{-\alpha_{i} s_{i j}(x)\left(1-s_{i j}(x)\right)}=\frac{s_{i k}(x)}{1-s_{i j}(x)}
$$

\section{A.3. Diversion Under Common Parametric Demands}

This section derives explicit formulas for the diversion ratio under common parametric forms for demand, focusing on whether or not the diversion ratio implied by a particular parametric form of demand is constant with respect to the magnitude of the price increase. We show that the IIA logit and linear demands model exhibit this property, while the log-linear and mixed logit models do not necessarily exhibit this property. We go through several derivations below.

\section{Linear Demand}

The diversion ratio under linear demand has the property that it does not depend on the magnitude of the price increase. We specify linear demand as:

$$
Q_{k}\left(P_{1}, \ldots, P_{J}\right)=\alpha_{k}+\sum_{j} \beta_{k j} P_{j}
$$

where $\frac{\partial Q_{k}}{\partial P_{j}} \equiv \beta_{k j}$ is the increase or decrease in $k$ 's quantity due to a one-unit increase in prouct j's price.

$$
D_{j k}\left(P_{1}, \ldots, P_{J}, x\right)=\frac{\beta_{k j}}{\beta_{j j}}
$$

Thus, for any change in $p_{j}$ from an infinitesimal price increase up to the choke price of $j$, the diversion ratio $D_{j k}$ is constant. This also implies that under linear demand, diversion is a global property. Any magnitude of price increase evaluated at any initial set of prices and quantities will result in the same measure of diversion. 


\section{Log-Linear Demand}

The log-linear demand model does not exhibit constant diversion with respect to the magnitude of the price increase. The log-linear model is specified as:

$$
\ln \left(Q_{k}\right)=\alpha_{k}+\sum_{\ell} \epsilon_{k \ell} \ln \left(P_{j}\right)
$$

As is well known $\epsilon_{j k}=\frac{\partial Q_{k}}{\partial P_{j}} \frac{P_{j}}{Q_{k}}$ and the diversion ratio can be re-written as:

$$
D_{j k}\left(P_{j}, x\right)=\frac{Q_{k}\left(P_{j}, x\right)}{Q_{j}\left(P_{j}, x\right)} \cdot \frac{\epsilon_{k j}}{\epsilon_{j j}}
$$

Under constant elasticity, the diversion ratio depends on where on the demand curve $P_{j}$ we are located. (This is similar to the fact that under linear demand, the own-price elasticity depends where on the demand curve we are located). As an additional challenge, secondchoice data is not interpretable because we cannot expect to set $Q_{j}=0$ and take $\log \left(Q_{j}\right)$.

\section{IIA Logit Demand}

The plain logit model exhibits IIA and proportional substitution, which implies that the diversion ratio does not depend on the magnitude of the price increase. The logit utility and market shares $q_{j}\left(P_{j}, x\right)=s_{j}\left(P_{j}, x\right) \cdot M$ are given by the well-known formulas:

$$
\begin{aligned}
u_{i j}\left(P_{j}, x\right) & =\beta x_{j}-\alpha P_{j}+\xi_{j}+\varepsilon_{i j} \\
S_{j}\left(P_{1}, \ldots, P_{j}, x\right) & =\frac{\exp \left[\beta x_{j}-\alpha P_{j}+\xi_{j}\right]}{1+\sum_{k \in \mathcal{J}} \exp \left[\beta x_{k}-\alpha P_{k}+\xi_{k}\right]}
\end{aligned}
$$

The logit derivatives also have well known formulas:

$$
\begin{aligned}
\frac{\partial S_{j}}{\partial P_{j}} & =\alpha S_{j}\left(1-S_{j}\right) & \frac{\partial S_{k}}{\partial P_{j}} & =-\alpha S_{j} S_{k} \\
\frac{\partial^{2} S_{j}}{\partial P_{j}^{2}} & =\alpha^{2}\left(1-2 S_{j}\right)\left(S_{j}-S_{j}^{2}\right) & \frac{\partial^{2} S_{k}}{\partial P_{j}^{2}} & =-\alpha^{2}\left(1-2 S_{j}\right) S_{j} S_{k}
\end{aligned}
$$

This means that under a logit demand the diversion from an infinitesimal price change is given by:

$$
\frac{\frac{\partial S_{k}}{\partial p_{j}}}{\left|\frac{\partial S_{j}}{\partial p_{j}}\right|}=\frac{\alpha S_{k} S_{j}}{\alpha S_{j}\left(1-S_{j}\right)}=\frac{S_{k}}{\left(1-S_{j}\right)}
$$


Meanwhile the diversion ratio exhibits constant treatment effects IFF the numerator in (10) is zero. This is true if $D_{j k}\left(P_{j}, x\right)=-\frac{\frac{\partial^{2} Q_{k}}{\partial P_{j}^{2}}}{\frac{\partial^{2} Q_{j}}{\partial P_{j}^{2}}}$. This property is easily verified for the logit:

$$
-\frac{\frac{\partial^{2} q_{k}}{\partial P_{j}^{2}}}{\frac{\partial^{2} q_{j}}{\partial P_{j}^{2}}}=\frac{\alpha^{2}\left(1-2 S_{j}\right) S_{j} S_{k}}{\alpha^{2}\left(1-2 S_{j}\right)\left(S_{j}-S_{j}^{2}\right)}=\frac{S_{k}}{1-S_{j}}
$$

For second choice data, it is helpful to define exponentiated indirect utility: $V_{k}=\exp \left[\beta x_{j}-\right.$ $\left.\alpha P_{j}+\xi_{j}\right]$ and write:

$$
\begin{aligned}
\frac{S_{k}(\mathcal{J}, x)-S_{k}(\mathcal{J} \backslash j, x)}{S_{j}(\mathcal{J}, x)} & =\frac{\frac{V_{k}}{1+\sum_{j^{\prime} \in \mathcal{J} \backslash j} V_{j^{\prime}}}-\frac{V_{k}}{1+\sum_{j^{\prime} \in \mathcal{J}} V_{j^{\prime}}}}{\frac{V_{j}}{1+\sum_{j^{\prime} \in \mathcal{J}} V_{j^{\prime}}}} \\
& =\frac{V_{k}}{1+\sum_{j^{\prime} \in \mathcal{J}} V_{j^{\prime}}} \cdot\left(\frac{1+\sum_{j^{\prime} \in \mathcal{J}} V_{j^{\prime}}}{1+\sum_{j^{\prime} \in \mathcal{J} \backslash j} V_{j^{\prime}}}-1\right) \frac{1}{V_{j}}=\frac{S_{k}(\mathcal{J}, x)}{1-S_{j}(\mathcal{J}, x)}
\end{aligned}
$$

In both cases, diversion is the ratio of the change in the marketshare of the substitute good divided by the share of consumers no longer buying the focal good (under the initial set of prices and product availability). It does not depend on any of the estimated parameters $(\alpha, \beta)$. It is also true that all individual diversion ratios are equal $D_{j k, i}=\frac{s_{k}}{1-s_{j}}$. This is also equal to the non-parametric discrete choice $A T T=E\left[D_{j k, i}(x) \mid d_{i j}=0\right]$.

\section{Nested Logit Demand}

Recall the estimating equation for the nested logit from Berry (1994):

$$
\ln s_{j t}-\ln s_{0 t}=x_{j t} \beta-\alpha p_{j t}+\sigma \ln s_{j \mid g, t}+\varepsilon_{j t}
$$

The derivatives of marketshare with respect to price are given by: ${ }^{56}$

$$
\begin{aligned}
& \frac{\partial s_{j}}{\partial p_{j}}=\alpha s_{j}\left(\frac{-1}{1-\sigma}+\frac{\sigma}{1-\sigma} s_{j \mid g}+s_{j t}\right) \\
& \frac{\partial s_{k}}{\partial p_{j}}=\left\{\begin{array}{ll}
\alpha s_{j}\left(\frac{\sigma}{1-\sigma} s_{k \mid g}+s_{k}\right) & \text { for }(j, k) \text { in same nest } \\
\alpha s_{j} s_{k} & \text { otherwise }
\end{array}\right\}
\end{aligned}
$$

\footnotetext{
${ }^{56}$ See Mansley et al. (2019) for derivatives worked out.
} 
And second derivatives:

$$
\begin{aligned}
\frac{\partial^{2} s_{j}}{\partial^{2} p_{j}} & =\alpha^{2}\left(\frac{1}{1-\sigma}-\frac{\sigma}{1-\sigma} \bar{s}_{j \mid g}-2 s_{j}\right)\left(\frac{1}{1-\sigma}-\frac{\sigma}{1-\sigma} \bar{s}_{j \mid g}-s_{j}\right) s_{j} \\
& -\alpha^{2} \frac{\sigma}{(1-\sigma)^{2}} s_{j} \bar{s}_{j \mid g}\left(1-\bar{s}_{j \mid g}\right) \\
\frac{\partial^{2} s_{k}}{\partial^{2} p_{j}} & =\alpha^{2} s_{k} s_{j}\left(s_{j}-\frac{1}{1-\sigma}\left(1-\sigma \bar{s}_{j \mid g}-(1-\sigma) s_{j}\right)\right) \quad \text { for different groups . } \\
\frac{\partial^{2} s_{k}}{\partial^{2} p_{j}} & =-\alpha^{2} \frac{1}{1-\sigma} s_{k}\left(1-\sigma \bar{s}_{k \mid g}-(1-\sigma) s_{k}\right)\left(s_{j}+\frac{\sigma}{1-\sigma} \bar{s}_{j \mid g}\right) \\
& +\alpha^{2} s_{k}^{2}\left(s_{j}+\frac{\sigma}{1-\sigma} \bar{s}_{j \mid g}\right)+\alpha^{2} \frac{\sigma}{1-\sigma} \frac{1}{1-\sigma} s_{k} \bar{s}_{j \mid g} \bar{s}_{k \mid g} \quad \text { for same groups. }
\end{aligned}
$$

It is helpful to define $Z\left(\sigma, s_{g}\right)=\left[\sigma+(1-\sigma) s_{g}\right] \in(0,1]$ and note that $Z\left(0, s_{g}\right)=s_{g}$ and $Z\left(1, s_{g}\right)=1$. When both products are in the same nest, the diversion ratio is given by:

$$
\begin{aligned}
-\frac{\frac{\partial s_{k}}{\partial p_{j}}}{\frac{\partial s_{j}}{\partial p_{j}}} & =-\frac{\frac{\sigma}{1-\sigma} s_{k \mid g}+s_{k}}{\frac{-1}{1-\sigma}+\frac{\sigma}{1-\sigma} s_{j \mid g}+s_{j}}=-\frac{\sigma s_{k \mid g}+s_{k \mid g} s_{g}(1-\sigma)}{-1+\sigma s_{j \mid g}+(1-\sigma) s_{j \mid g} s_{g}}=-\frac{s_{k \mid g}\left[\sigma+(1-\sigma) s_{g}\right]}{-1+s_{j \mid g}\left[\sigma+(1-\sigma) s_{g}\right]} \\
& =\frac{s_{k \mid g} \cdot Z\left(\sigma, s_{g}\right)}{1-s_{j \mid g} \cdot Z\left(\sigma, s_{g}\right)}=\frac{s_{k \mid g}}{Z^{-1}\left(\sigma, s_{g}\right)-s_{j \mid g}} \equiv D_{j k}^{*}
\end{aligned}
$$

Observe that $Z^{-1}\left(\sigma, s_{g}\right) \geq 1$. Also notice that we get diversion ratios proportional to within group share $s_{k \mid g}$.

If both products are in different nests, we need to re-scale the numerator by $\frac{s_{k}}{\frac{\sigma}{1-\sigma} s_{k \mid g}+s_{k}}=$ $\frac{s_{g}(1-\sigma)}{\sigma+(1-\sigma) s_{g}}=s_{g}(1-\sigma) Z^{-1}\left(\sigma, s_{g}\right)$. We must also keep track of which product's group share we are referring to. It is helpful to use the second to last expression in the derivation for the same nest:

$$
\begin{aligned}
-\frac{\frac{\partial s_{k}}{\partial p_{j}}}{\frac{\partial s_{j}}{\partial p_{j}}} & =\frac{s_{k \mid g} \cdot Z\left(\sigma, s_{g(k)}\right)}{1-s_{j \mid g} \cdot Z\left(\sigma, s_{g(j)}\right)} \cdot s_{g(k)}(1-\sigma) Z^{-1}\left(\sigma, s_{g(k)}\right) \\
& =\frac{s_{k}(1-\sigma)}{1-s_{j \mid g} \cdot Z\left(\sigma, s_{g(j)}\right)} \equiv D_{j k}^{* *}
\end{aligned}
$$

Notice that we get diversion ratios proportional to overall share $s_{k}$.

We can relate the diversion ratio of two products within the group $D_{j k}^{*}$ to the diversion 
ratio of two products in different groups $D_{j k}^{* *}$ by:

$$
D_{j k}^{* *}=D_{j k}^{*} \cdot \frac{s_{g(k)} \cdot(1-\sigma)}{Z\left(\sigma, s_{g(j)}\right)}
$$

As $\sigma \rightarrow 1$ everyone stays within the group and $D_{j k}^{*}=\frac{s_{k \mid g}}{1-s_{j \mid g}}$ and $D_{j k}^{* *}=0$.

As $\sigma \rightarrow 0$ we collapse to the logit and $D_{j k}^{*}=D_{j k}^{* *}=\frac{s_{k \mid g}}{\frac{1}{s_{g}}-s_{j \mid g}} \cdot \frac{s_{g}}{s_{g}}=\frac{s_{k}}{1-s_{j}}$.

We can also check the curvature property in (9). We are interested in the ratio (check for different groups):

$$
\begin{aligned}
-\frac{\frac{\partial^{2} s_{k}}{\partial^{2} \delta_{j}}}{\frac{\partial^{2} s_{j}}{\partial^{2} \delta_{j}}}= & -\frac{s_{k} s_{j}\left(s_{j}-\frac{1}{1-\sigma}\left(1-\sigma \bar{s}_{j \mid g}-(1-\sigma) s_{j}\right)\right)}{\left(\frac{1}{1-\sigma}-\frac{\sigma}{1-\sigma} \bar{s}_{j \mid g}-2 s_{j}\right)\left(\frac{1}{1-\sigma}-\frac{\sigma}{1-\sigma} \bar{s}_{j \mid g}-s_{j}\right) s_{j}-\frac{\sigma}{(1-\sigma)^{2}} s_{j} \bar{s}_{j \mid g}\left(1-\bar{s}_{j \mid g}\right)} \\
& =\frac{(1-\sigma) s_{k}\left(1-\sigma \bar{s}_{j \mid g}-2(1-\sigma) s_{j}\right)}{\left(1-\sigma \bar{s}_{j \mid g}-2(1-\sigma) s_{j}\right)\left(1-\sigma \bar{s}_{j \mid g}-(1-\sigma) s_{j}\right)-\sigma \bar{s}_{j \mid g}\left(1-\bar{s}_{j \mid g}\right)} \\
& =\frac{(1-\sigma) s_{k}}{\left(1-\sigma \bar{s}_{j \mid g}-(1-\sigma) s_{j}\right)-\frac{\sigma \bar{s}_{j \mid g}\left(1-\bar{s}_{j \mid g}\right)}{\left(1-\sigma \bar{s}_{j \mid g}-2(1-\sigma) s_{j}\right)}}
\end{aligned}
$$

If the second term in the denominator were zero, observe that:

$$
D_{j k}^{* *}=\frac{(1-\sigma) s_{k}}{\left(1-\sigma \bar{s}_{j \mid g}-(1-\sigma) s_{j}\right)}
$$

Since the second term is not equal to zero unless $s_{j \mid g} \in\{0,1\}$ the nested logit does not appear to satisfy the curvature property. This means that diversion ratios do not exhibit constant treatment effects. We have confirmed via simulation that second choice diversion ratios are not equal to diversion ratios measured by marginal price changes.

\section{Random Coefficients Logit Demand}

Random Coefficients Logit demand relaxes the IIA property of the plain Logit model, which can be desireable empirically and leads to non-constant treatment effects measures of diversion ratios. That is, a change in price or quality may lead to a different average estimate of diversion ratios than second choice data. Intuitively, a small price increase might induce diversion from the most price-sensitive consumers, while a larger price increase might see substitution from a larger set of consumers. If price sensitivity is correlated with other tastes, then the diversion ratio could differ with the magnitude of the price increase. 
We can repeat the same exercise for the logit model with random coefficients, by discretizing a mixture density over $i=1, \ldots, I$ representative consumers, with population weight $w_{i}$ :

$$
u_{i j}=\overbrace{\underbrace{z_{j} \beta+\xi_{j t}}_{\delta_{j}}+\mu_{i j}}^{V_{i j t}}+\varepsilon_{i j}
$$

Using the chain rule (for an arbitrary $z_{j}$ including price) we can write:

$$
\frac{\partial V_{i j t}}{\partial z_{j t}}=\frac{\partial V_{i j t}}{\partial \delta_{j t}} \cdot \frac{\partial \delta_{j t}}{\partial z_{j t}}+\frac{\partial V_{i j t}}{\partial \mu_{i j t}} \cdot \frac{\partial \mu_{i j t}}{\partial z_{j t}}
$$

Because the random coefficients model is a single index model, any $z_{j}$ which affects only the mean utility component $\delta_{j}$ and not the unobserved heterogeneity $\mu_{i j}$ yields the same marginal diversion measure. If all agents agree on their preferences for $z_{j}$ : $\frac{\partial \mu_{i j}}{\partial z_{j}} \equiv 0$ and $\frac{\partial V_{i j t}}{\partial z_{j t}}=1 \cdot \frac{\partial \delta_{j t}}{\partial z_{j t}}=\beta_{z}$. This has the advantage that the (marginal/infinitesimal) diversion ratio can be identified in the random coefficients logit model even when a (common) price parameter $\alpha$ is not identified (as long as $p_{j}$ does not have a random coefficient). This can be seen in (A.7) which does not depend on $\partial V_{i j} / \partial p_{j}$.

$$
\begin{aligned}
& \frac{\frac{\partial S_{k}}{\partial p_{j}}}{\left|\frac{\partial S_{j}}{\partial p_{j}}\right|}=\frac{\int s_{i j} s_{i k} \frac{\partial V_{i k}}{\partial p_{j}}}{\int s_{i j}\left(1-s_{i j}\right) \frac{\partial V_{i j}}{\partial p_{j}}} \rightarrow \frac{\int s_{i j} s_{i k}}{\int s_{i j}\left(1-s_{i j}\right)} \\
& \frac{S_{k}(\mathcal{J}, x)-S_{k}(\mathcal{J} \backslash j, x)}{S_{j}(\mathcal{J}, x)}=\frac{\int \frac{e^{V_{i k}}}{1+\sum_{l \in a \backslash j} e^{V_{i l}}}-\frac{e^{V_{i k}}}{1+\sum_{l^{\prime} \in a} e^{V_{i l^{\prime}}}}}{\int-\frac{e^{V_{i j}}}{1+\sum_{l \in a} e^{V_{i l}}}} \quad \rightarrow \frac{1}{s_{j}} \int \frac{s_{i j} s_{i k}}{\left(1-s_{i j}\right)}
\end{aligned}
$$

Even in the case where consumers have homogenous tastes for $z$ so that $\beta_{i z}=\beta_{z}$, the two diversion measures do not agree. Each individual exhibits constant diversion $D_{j k, i}=$ $\frac{s_{i k}}{1-s_{i j}}$, but weights on individuals vary depending on how diversion is measures, so that diversion is only constant if $s_{i j}=s_{j}$. The more correlated $\left(s_{i j}, s_{i k}\right)$ are (and especially as they are correlated with $\alpha_{i}$ ) the greater the discrepancy between the two measures of average diversion. The various weights are all described in Table 2 in the main text.

\section{B. Additional Empirical Results}

In this section we present some additional results from our empirical applications to the Berry et al. (1999) automobile data and the Nevo (2000b) (fake) cereal data. 
In Table B.1 we present the mean taste parameters for various product characterisitcs. These are sometimes referred to as the $\beta$ or $\bar{\beta}$ parameters. By and large they have the antcipated signs. In automobiles consumers prefer faster vehicles (more horsepower relative to weight), air conditioning, and size. In the cereal example, consumers prefer sugary cereals (on average) and dislike mushy cereals (on average).

In Table B.2 we compute the pairwise correlation between each of the treatment effects parameters (price change, quality change, second choice data) as well as the simplified models (Logit/ATT, and Nested Logit). For this exercise we consider diversion among all pairs of products. As our weights predict, the correlation between the second-choice data and smallquality changes is very high (even higher than correlation with the small price changes). The correlation between small price change diversion and small quality change diversion is much higher in the Nevo example than the BLP example and is driven by differences in the distribution of $\left|\alpha_{i}\right|$ which is more dispersed in the BLP example. This is a fact we highlight below in Figure B.1.

As one might also expect, the correlation between the nested logit and logit models is high, and the correlation between the nested logit (or logit) models and random coefficients models (for any treatment effects parameter) is much lower. This is again more pronounced in the BLP example than the Nevo example where there is less overall heterogeneity in the $D_{j k, i}(x)$ measures. 


\begin{tabular}{lllll}
\hline & Best Practices & $\Sigma_{\text {cons }}=\pi_{\text {cons }}=0$ & $\Sigma_{p}=\pi_{p}=0$ & Rescaled Shares \\
\hline BLP & & & & \\
\hline price/inc & -51.254 & -49.175 & -0.355 & -11.277 \\
$\beta_{\text {cons }}$ & $(5.847)$ & $(7.104)$ & $(0.030)$ & $(2.218)$ \\
& -5.372 & -5.714 & -9.608 & -6.551 \\
$\beta_{\text {HP } / \text { weight }}$ & $(0.521)$ & $(0.450)$ & $(1.577)$ & $(0.662)$ \\
$\beta_{\text {air }}$ & $(0.710)$ & 3.070 & 4.879 & 1.274 \\
& 0.513 & $(0.891)$ & $(2.746)$ & $(0.770)$ \\
$\beta_{\text {MP\$ }}$ & $(0.332)$ & 0.728 & 2.682 & -0.050 \\
$\beta_{\text {size }}$ & -0.005 & $(0.282)$ & $(10.265)$ & $(0.287)$ \\
& $(0.156)$ & 0.239 & 0.041 & 0.522 \\
\hline Nevo & 3.614 & $(0.088)$ & $(0.157)$ & $(0.113)$ \\
\hline \multirow{2}{*}{$\alpha_{\text {price }}$} & $(0.423)$ & 3.567 & 2.585 & 4.209 \\
$\beta_{\text {cons }}$ & -31.125 & $(0.438)$ & $(0.945)$ & $(0.242)$ \\
$\beta_{\text {sugar }}$ & $(4.700)$ & -42.642 & & \\
$\beta_{\text {mushy }}$ & -2.925 & $(3.627)$ & -30.939 & -36.280 \\
& $(0.343)$ & 0.373 & $(0.913)$ & $(2.507)$ \\
\hline & $(0.234$ & $(0.331)$ & -1.977 & -4.165 \\
& -0.886 & 0.109 & $(0.342)$ & $(0.337)$ \\
& $(0.439)$ & $(0.035)$ & 0.188 & 0.211 \\
& & $(0.427)$ & $(0.035)$ & $(0.034)$ \\
& & & -0.867 & $(0.426)$ \\
\hline
\end{tabular}

Table B.1: Linear Utility Demand Parameters

\begin{tabular}{lrrrrr}
\hline & $D_{j k}(p)$ & Small Quality Change & Second Choice & Logit & Nested Logit $D_{j k}(p)$ \\
\hline$D_{j k}(p)$ & 1.000 & 0.912 & 0.909 & 0.346 & 0.329 \\
Small Quality Change & 0.912 & 1.000 & 0.999 & 0.399 & 0.377 \\
Second Choice & 0.909 & 0.999 & 1.000 & 0.394 & 0.372 \\
Logit & 0.346 & 0.399 & 0.394 & 1.000 & 0.916 \\
Nested Logit $D_{j k}(p)$ & 0.329 & 0.377 & 0.372 & 0.916 & 1.000 \\
\hline & $D_{j k}(p)$ & Small Quality Change & Second Choice & Logit & Nested Logit $D_{j k}(p)$ \\
\hline$D_{j k}(p)$ & 1.000 & 0.990 & 0.991 & 0.682 & 0.676 \\
Small Quality Change & 0.990 & 1.000 & 0.999 & 0.725 & 0.721 \\
Second Choice & 0.991 & 0.999 & 1.000 & 0.716 & 0.712 \\
Logit & 0.682 & 0.725 & 0.716 & 1.000 & 0.981 \\
Nested Logit $D_{j k}(p)$ & 0.676 & 0.721 & 0.712 & 0.981 & 1.000 \\
\hline
\end{tabular}

Table B.2: Pairwise Correlation Among Treatment Effects Parameters 


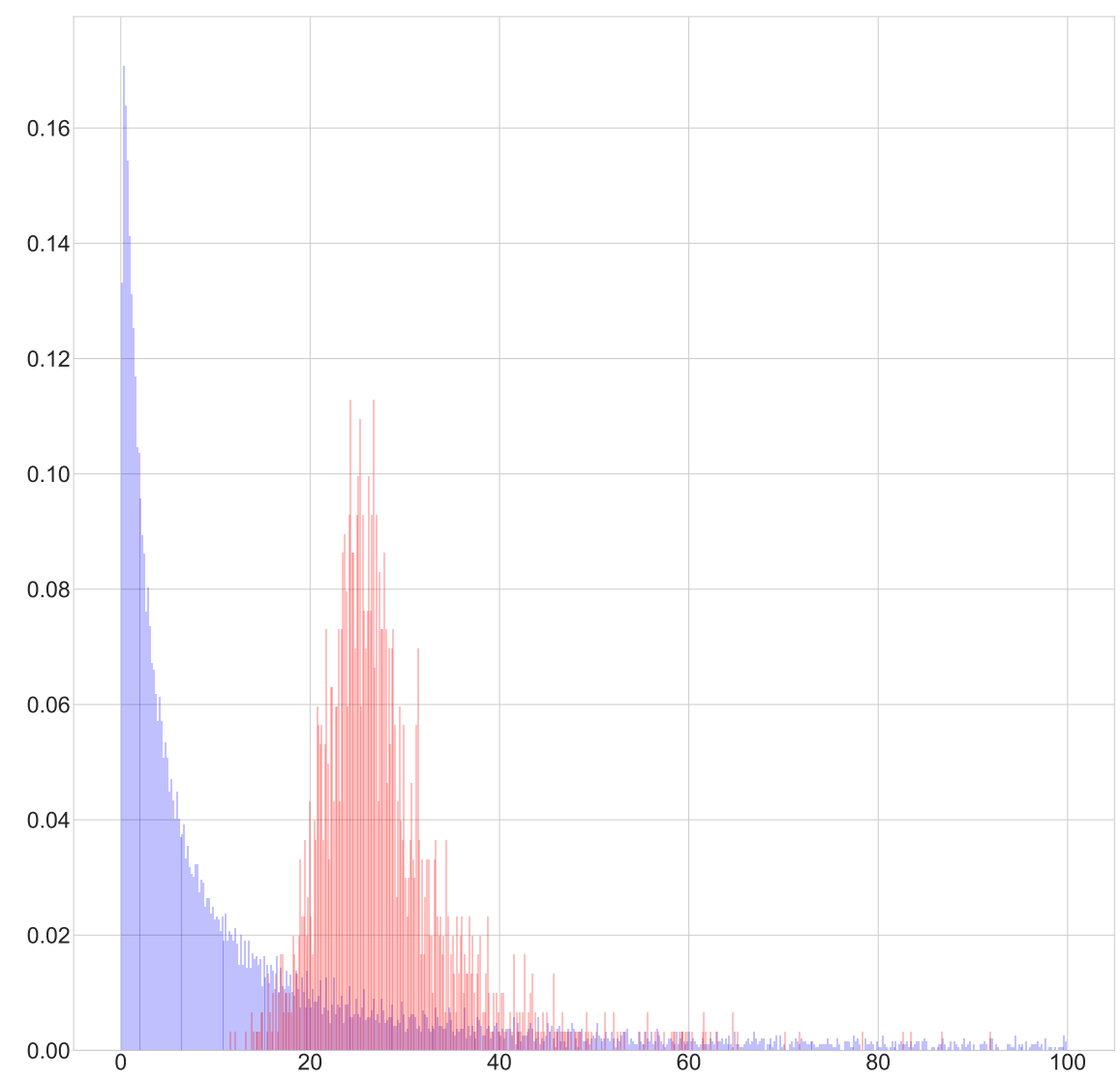

Figure B.1: Density of $\alpha_{i}$ for BLP (Blue) and Nevo (Red) Data 